\title{
Effect of Inclination Angle during Melting and Solidification of a Phase Change Material using a Combined Heat Pipe-Metal Foam or Foil Configuration
}

\author{
Michael J. Allen ${ }^{\mathrm{a}}$ \\ Nourouddin Sharifi ${ }^{\mathrm{a}}$ \\ Amir Faghri, ${ }^{\text {,** }}$ \\ Theodore L. Bergman ${ }^{\mathrm{b}}$ \\ ${ }^{a}$ Department of Mechanical Engineering, University of Connecticut, \\ 191 Auditorium Road, Storrs, CT 06269-3139, USA \\ ${ }^{\mathrm{b}}$ Department of Mechanical Engineering, University of Kansas, \\ Lawrence, KS 66045, USA
}

* Corresponding Author

Amir Faghri

faghri@engr.uconn.edu

Ph: +1 8604860419 


\begin{abstract}
Experiments are performed to analyze the impact of system inclination (ranging from $0^{\circ}$ to $90^{\circ}$ ) on the melting and solidification of a phase change material (PCM) in a cylindrical enclosure. Heat transfer occurs through a concentrically located heat pipe (HP) or solid copper rod and an underlying copper disc. The HP may also be combined with aluminum foils and foam. Six configurations are investigated: HP-Foil-PCM, HP-Foam-PCM, HP-PCM, Rod-PCM, Foam-PCM and non-enhanced PCM. The PCM liquid fraction histories, temperature distributions and photographs provide insight into the influence of the inclination angle, as well as the three-dimensional melting phenomena. Experimental measurements indicate that the system orientation has a minimal effect on the solidification rates for nearly all case studies due to conduction-dominated heat transfer. However, during melting, the presence of natural convection may significantly alter the liquid fraction histories for systems without foam or foils. For the HP-PCM and Rod-PCM configurations with a horizontal orientation, the liquid fraction may be increased by up to 0.09 and 0.20 compared to a vertical orientation for a system with and without heat transfer through the base, respectively. For the HP-Foil-PCM and HP-Foam-PCM configurations, a vertical orientation achieved a slightly higher liquid fraction by approximately 0.03 and 0.05 , respectively, relative to horizontal orientation. This may be attributed to the flow of the HP's internal working fluid, in which gravity assists the return of the liquid working fluid to the HP evaporator in a vertical orientation. The time for complete melting and solidification for the HP-Foil-PCM configuration was reduced to $11 \%$ and $3 \%$ of that for a non-enhanced system, respectively, regardless of orientation. Overall, the combination of a HP with foils or foam may achieve much higher melting and solidification rates with respect to a non-enhanced system.
\end{abstract}

Keywords: Heat transfer enhancement, Latent heat thermal energy storage, Phase change material (PCM), Heat pipe, Foil, Foam, Inclination angle 


\section{Introduction}

The utilization of energy storage may allow for renewable energy power systems, such as solarthermal, to increase in efficiency as well as become economically competitive with traditional power plants. While various energy storage methods are available, latent heat thermal energy storage (LHTES) using a phase change material (PCM) is attractive for thermal systems. Currently, sensible heat thermal energy storage is more common, yet, LHTES may have a higher potential for utilization due to its higher energy density, nearly isothermal operation and reduced size [1]. However, most PCMs have low thermal conductivities which has limited the use of LHTES systems in the past [2]. Therefore, various heat transfer enhancement approaches have been proposed and implemented such as: heat transfer fins $[3,4]$, foils (fin thickness less than $0.2 \mathrm{~mm}$ ) [5], micro-encapsulation [6], macro-encapsulation [7], nanoparticles [8], porous media (such as metal foams and expanded graphite) [9] and heat pipes (HPs) [10,11].

The implementation of HPs into PCMs has been patented by Faghri $[12,13]$, as they can efficiently transfer large amounts of heat passively through small cross-sectional areas [14]. The incorporation of HPs into a PCM to increase melting and solidification rates has been investigated [1,10,11,15-18]. As enhancers, HPs allow for deeper thermal penetration into the PCM. Other approaches, such as embedding foam or foils into the PCM, increase the effective thermal conductivity of a PCM-enhancer composite. For example, Zhao et al. [19] reported that the overall heat transfer rates can be increased by up to 10 times with the inclusion of metal foam, depending on the choice of foam and PCM. Similarly, Sugawara et al. [5] reported that installing copper foils $(0.03 \mathrm{~mm}$ thickness, $5 \%$ foil volume fraction) onto a heat transfer fluid (HTF) tube surrounded by PCM can reduce the complete melting (solidification) time to a tenth (eighteenth) of that for a case without foils. Other studies involving metallic heat transfer enhancers have shown comparable results which will not be discussed here.

Embedding metal enhancers, such as foam or foils, into PCMs may significantly suppress the positive contribution of natural convection during melting. Therefore, the improvement in conduction 
within a PCM should outweigh the suppression of natural convection. Since many studies of Foam-PCM systems have been focused towards electronic cooling, length scales typically in the range of approximately $15 \mathrm{~mm}$ to $50 \mathrm{~mm}$ have been considered [19-24]. However, as the distance between the solid-liquid interface and the heat transfer surface increases for larger scale systems, foams or foils may be ineffective, hence the need to increase the thermal penetration depth within the metal enhancer.

The combination of HPs and aluminum foils was first proposed by Sharifi et al. [25]. The authors experimentally and numerically investigated the solidification and melting in a vertical cylindrical enclosure heated / cooled by a concentric HP which penetrated an array of horizontal foils within the PCM enclosure. Heat transfer rates were increased with a HP-Foil-PCM configuration by 3 and 9 times compared to a similar Rod-PCM system during melting and solidification, respectively, with a foil volume fraction of $1.2 \%$.

A similar system was investigated by Allen et al. [26] which included the combination of a HP and aluminum foam, where the foam porosities ranged from 0.870 to 0.987 . The HP-Foil-PCM configuration was reported to have improved performance relative to the HP-Foam-PCM configuration. The HP-Foil-PCM configuration was capable of reducing the complete melting and solidification times from $200 \mathrm{~min}$ and $150 \mathrm{~min}$ for a Rod-PCM configuration to $13 \mathrm{~min}$ and $11 \mathrm{~min}$, respectively. The HPFoil-PCM and HP-Foam-PCM configurations increased the heat transfer rates by nearly 15 and 7 (8 and 6) times, respectively, relative to the Rod-PCM configuration during melting (solidification) with a porosity of approximately 0.957 for the foil-PCM and foam-PCM composites.

In the past, the combined HP and foam or foil systems were only studied in the vertical orientation $[25,26]$. However, if an enhancement technique is to be implemented into systems which experience various inclination angles, such as portable electronics, it must operate regardless of its orientation. For example, the time varying performance of a HP assisted LHTES has been investigated for an emerging application involving a dish-Stirling system for solar power production $[27,28]$. The authors proposed that the LHTES be attached directly onto the dish which will impose a varying inclination angle with the time of day, as the dish is designed to follow the trajectory of the sun. 
In conduction-dominated systems, orientation is mainly insignificant. However, for systems involving HPs, the internal evaporation and condensation processes vary depending on the HP orientation. Also, natural convection within the PCM strongly depends on the location of the hot surface relative to the solid PCM. Therefore, system orientation may alter the melting rates.

Ye et al. [29] numerically investigated the effect of system inclination angle on the melting of a paraffin $\left(T_{m} \approx 27^{\circ} \mathrm{C}\right)$ in a quadrantal cavity heated from the curved wall. Without any heat transfer enhancement within the PCM, the complete melting time for the system when the heated curved surface was at bottom of the system and the gravity vector bisects the quadrantal cavity was approximately $13 \%$ of that when it was rotated $180^{\circ}$. In a related study, Kamkari et al. [30] experimentally melted a lauric acid $\left(T_{m} \approx 45^{\circ} \mathrm{C}\right)$ in a rectangular enclosure with varying tilt angles, with $0^{\circ}$ corresponding to heating from below. The complete melting time was reduced by approximately $53 \%$ and $35 \%$ for the $0^{\circ}$ and $45^{\circ}$ orientations, respectively, relative to $90^{\circ}$ with side wall heating. Hence, orientation alone may significantly alter the heat transfer rates in PCM systems due to changing natural convection flow patterns. Similar observations have been reported elsewhere [31-34].

With regard to HP-PCM systems, few have considered HP orientation with the exception of Nithyanandam and Pitchumani [35-38] and Shabgard et al. [16]. These works numerically investigated the effects of the orientation and number of HPs in a shell and tube PCM system. In [35], the effectiveness for a case with two horizontal HPs that penetrate the tube on opposite sides was increased by approximately $20 \%$ relative to a case with two vertical HPs. However, Shabgard et al. [16] reported that a similar configuration containing two vertical HPs had a higher effectiveness.

The improved heat transfer rates in PCM systems obtained for a combined enhancement approach including a HP and foam or foils in $[25,26]$ and, to the authors' knowledge, the lack of a fundamental study in the literature involving the effect of orientation on a HP-enhanced PCM system containing a single HP motivate this work. Furthermore, in order to compare the effect of adding a HP vs. foam as individual heat transfer enhancement techniques, heat transfer from the base of the enclosure is included in this work. In this study, the orientation of the HP-Foil-PCM, HP-Foam-PCM, HP-PCM, Rod-PCM, 
Foam-PCM and non-enhanced PCM configurations are experimentally investigated. The objective is to provide detailed information (temperature distribution, volumetric liquid fraction histories and photographic observations) during both melting and solidification for systems involving tilting.

\section{Experimental apparatus}

A layout of the experimental apparatus is shown in Fig. 1. The PCM (n-octadecane, properties in Table 1) is contained in an acrylic tube (41 mm inner diameter, $60 \mathrm{~mm}$ height, $4.6 \mathrm{~mm}$ wall thickness) and is subject to heat transfer from a copper disc (63 mm outer diameter, $5 \mathrm{~mm}$ thickness) at the base of the tube, as well as a concentrically located HP or rod. The PCM is further enhanced with either foam or foils. To determine the effect of heat transfer through the base of the enclosure for the HP-PCM configuration only, the copper disc was replaced with the combination of an acrylic plate $(5 \mathrm{~mm}$ thickness) and an acrylic disc (50.2 $\mathrm{mm}$ diameter, $5 \mathrm{~mm}$ thick). A $2 \mathrm{~mm}$ recess is included in the acrylic disc to provide a layer of air as an insulating material to minimize heat transfer directly from the HTF to the PCM through the acrylic disc and plate.

A Lauda Brinkmann RE107 bath circulator is used to circulate water as a HTF to provide the driving potential for heat transfer. The HTF is contained in an enclosure fabricated from $10 \mathrm{~mm}$ thick acrylic plates with overall dimensions of $140 \mathrm{~mm} \times 100 \mathrm{~mm} \times 100 \mathrm{~mm}$. A HP (Fujikura: copper-water, grooved wick) or rod (copper) of length $150 \mathrm{~mm}$ and outer diameter $6 \mathrm{~mm}$, and the copper disc facilitate heat transfer between the HTF and the PCM. Additionally, 25 copper foils $(39 \mathrm{~mm}$ outer diameter, $5 \mathrm{~mm}$ inner diameter, $0.025 \mathrm{~mm}$ thickness) were press-fit onto the section of the HP located within the HTF.

The acrylic tube that contains the PCM is sealed by the disc (copper or acrylic) and an acrylic plate of thickness $25 \mathrm{~mm}$ as seen in Fig. 1 (a). At each interface, silicone sealant was used to seal and secure each component (HP, disc, acrylic tube and acrylic plate), while four all-threaded rods compress the entire system. The acrylic plate contains a pathway leading to a network of aluminum pipes, with an outer diameter (thickness) of $14 \mathrm{~mm}(2 \mathrm{~mm})$, which forms an air chamber to accommodate the volume change of the PCM due to different solid and liquid densities. After assembly, the entire apparatus is 
placed in an acrylic enclosure of dimensions $200 \mathrm{~mm} \times 130 \mathrm{~mm} \times 300 \mathrm{~mm}$ to thermally insulate the system from the environment, as well as to allow visual observation of the melting and solidification processes. Additionally, fiberglass insulation ( $80 \mathrm{~mm}$ thick) was wrapped around the network of aluminum pipes which extended beyond the acrylic enclosure.

In this study, Duocel® aluminum foam (alloy 6101-T6 containing about $98 \%$ aluminum), with a porosity $(\varphi)$ of 0.95 and a pore density of 20 pores per inch, was utilized in the HP-Foam-PCM and Foam-PCM configurations. Aluminum foils (alloy 8011, also with approximately $98 \%$ aluminum content) with outer diameter $39 \mathrm{~mm}$ and thickness $0.025 \mathrm{~mm}$ were used in the HP-Foil-PCM configuration with $\varphi=0.945$. The foils and foam, of annular construction, each originally had an inner diameter of $5 \mathrm{~mm}$ to ensure that thermal contact is maintained with a concentric HP after a press-fit installation. In order to secure and thermally bond the foam to the copper disc, a thin layer of Omegabond ${ }^{\circledR} 101$ thermal epoxy was implemented [39].

Upon melting, expansion of the PCM (mass, $m=60 \pm 0.2 \mathrm{~g}$ ) causes a reduction in the air volume within the air expansion network (comprising the volume of the machined portion of the upper acrylic plate and the aluminum pipe structure in Fig. 1(a)) thereby increasing the air pressure. The fixed mass of PCM was chosen so that $100 \%$ of the liquid PCM for each case study is contained within the domain of the acrylic cylinder and acrylic plate of Fig. 1(a) to minimize unwanted heat transfer with the aluminum pipe. Note that the PCM does not come in contact with the aluminum pipe and solidification of the PCM was not observed to occur in the air expansion network throughout this experiment. To measure the air pressure change, a Sper Scientific (model PS100 - 2 bar) differential pressure transducer is attached to the air expansion chamber, collected with a pressure meter (Sper Scientific, Model 840065) and recorded using Lutron801 software.

During assembly, a total of 18 Teflon-coated, $254 \mu \mathrm{m}$ diameter chromel-alumel (K-type) thermocouples were inserted into through-holes in the acrylic tube at the proper radial $\left(r_{1}=9 \mathrm{~mm}, r_{2}=15\right.$ $\mathrm{mm})$, axial $\left(z_{1}=15 \mathrm{~mm}, z_{2}=30 \mathrm{~mm}, z_{3}=45 \mathrm{~mm}\right)$ and polar $\left(\theta_{1}=0^{\circ}, \theta_{2}=90^{\circ}, \theta_{3}=180^{\circ}\right)$ coordinates within the PCM domain with an estimated placement accuracy of $\pm 1 \mathrm{~mm}$, and then secured with silicone 
sealant as seen in Fig. 1. Thermocouples were also installed on the HP in the PCM $(z=55 \mathrm{~mm})$, on the HP in the HTF $(z=-20 \mathrm{~mm}$ and $z=-80 \mathrm{~mm}$ ) and on the copper disc (two on both the PCM and HTF sides at $r=12 \mathrm{~mm}$ with $\theta_{1}=0^{\circ}$ and $\theta_{3}=180^{\circ}$ ) using a small drop of thermal epoxy (Omegabond ${ }^{\circ} 101$ ) and aluminum foil tape. A thermocouple was also installed in the air chamber and at the water inlet and outlet. The thermocouples were calibrated using the freezing and boiling points of distilled water, and were constructed from the same spool of wire to minimize bias errors when calculating temperature differences. The thermocouple temperature uncertainty was estimated as $\pm 1{ }^{\circ} \mathrm{C}$ while a National Instruments data acquisition (NI CDAQ-9172) system and LabVIEW software were used to collect and record data at $1 \mathrm{~s}$ intervals, respectively.

In order to set the system inclination, an angle finder (Johnson Level \& Tool, model \# 750) is utilized to ensure that it is within $\pm 2^{\circ}$ of the desired angle. The following system inclination angles are considered: $\alpha=0^{\circ}, 30^{\circ}, 60^{\circ}$ and $90^{\circ}$, with $\alpha=0^{\circ}$ denoting the vertical orientation as seen in Fig. 1 .

To quantify the performance of each configuration, the volumetric liquid fraction is calculated using the measured air temperature and pressure change as described in [25]. To further analyze the effect of tilting, photographs were taken periodically, using a Panasonic Lumix (model: DMC-FH24) camera.

For a meaningful comparison between the HP-Foil-PCM and HP-Foam-PCM configurations, the porosity of the foil-PCM and foam-PCM composites must be identical. Since the porosity of the metal foam is fixed at the manufactured value, the mass of the foils must be adjusted to that of the foam by altering the number of foils to establish an identical metal enhancer-PCM porosity, calculated by:

$$
\varphi=\frac{V_{\text {void }}}{V_{\text {total }}}=\frac{V_{p c m}}{V_{p c m}+V_{m e}} \approx \frac{m_{p c m} / \rho_{p c m, s}}{m_{p c m} / \rho_{p c m, s}+m_{m e} / \rho_{m e}}
$$

Note that individual foils are not porous as they are fabricated from common household aluminum foil, and the PCM occupies the region between foils.

\section{Experimental procedure}

Melting and solidification of the HP-Foil-PCM, HP-Foam-PCM, Foam-PCM, HP-PCM, RodPCM and non-enhanced PCM configurations were investigated in this study. A fixed mass of $60 \mathrm{~g}$ of 
PCM was degassed in a reduced pressure environment before filling the enclosure. The entire system was shaken to remove any entrapped air within the foam or between foils. In the study, the foil-PCM and foam-PCM composites for the HP-Foil-PCM and HP-Foam-PCM configurations had a porosity of about 0.95 .

The initial temperature of the PCM was set as $24^{\circ} \mathrm{C}\left(31^{\circ} \mathrm{C}\right)$ during melting (solidification) for all cases by using the water bath circulator. After equilibration at the set point temperature, solidification (melting) was initiated by flowing water at $11^{\circ} \mathrm{C}\left(45^{\circ} \mathrm{C}\right)$ to establish a nominal driving temperature of $|\Delta T|=17^{\circ} \mathrm{C}$ between the PCM melting temperature and the HTF temperature. Two additional driving temperatures of $|\Delta T|=8{ }^{\circ} \mathrm{C}$ and $|\Delta T|=25^{\circ} \mathrm{C}$ were also considered, which correspond to inlet HTF temperatures of $20^{\circ} \mathrm{C}$ and $3{ }^{\circ} \mathrm{C}\left(36^{\circ} \mathrm{C}\right.$ and $\left.53{ }^{\circ} \mathrm{C}\right)$, respectively, during solidification (melting). Each experiment is terminated once a constant differential air pressure is observed, indicating complete melting or solidification. To check repeatability, each experiment was conducted twice with minor (approximate 1 $\%)$ differences in the liquid fraction between two distinct cases. The average measured values obtained from two experiments are presented here.

The temperature distribution, photographs, liquid fraction $\left(f_{l}\right)$, and time for $95 \%$ complete melting $\left(t_{m}\right)$ and solidification $\left(t_{s}\right)$ are the main figures of merit used to quantify the performance of each system. Of these parameters, the liquid fraction is defined based on the change in air pressure and temperature in the same manner as [25]. A sequential perturbation-based uncertainty analysis [40] is carried out in a similar manner as [25] and will not be repeated in detail. The average uncertainty in liquid fraction ranged from approximately \pm 0.10 to \pm 0.15 . From the liquid fraction histories, a few additional parameters may be defined including a relative effectiveness, melting rate and time ratio for $95 \%$ complete phase change.

\section{Results and discussion}

With respect to the base case of the non-enhanced PCM configuration, the relative effectiveness at $95 \%$ complete phase change is defined as: 


$$
\begin{gathered}
\varepsilon_{m}=\frac{f_{l}\left(t_{m}\right)}{f_{l, b c}\left(t_{m}\right)} \\
\varepsilon_{s}=\frac{1-f_{l}\left(t_{s}\right)}{1-f_{l, b c}\left(t_{s}\right)}
\end{gathered}
$$

where $f_{l}\left(t_{m}\right)=0.95$ and $f_{l}\left(t_{s}\right)=0.05$. Since the outer diameter of the foils and foam is slightly smaller than the inner diameter of the acrylic tube, there is a small region of PCM near the acrylic tube that does not contain the metal enhancer. Therefore, $95 \%$ melting and solidification are taken as the values of interest.

An additional figure of merit is the melting rate. Since the liquid fraction histories are fairly linear in the range of conditions studied, with the exception of the HP-PCM, Rod-PCM and Foam-PCM cases with $\alpha=90^{\circ}$, the melting rate at $95 \%$ phase change may be defined as:

$$
r_{m}=\frac{0.95 m_{p c m}}{t_{m}}
$$

Note that a solidification rate could be similarly defined as Eq. (5), however, it is not a good measure of performance as the liquid fraction history is not linear due to the conduction-dominated heat transfer, as will be shown later.

The final figure of merit that will be quantified in this work is the time ratio for $95 \%$ complete melting $\left(t / t_{b c}\right)_{m}$ and $95 \%$ complete solidification $\left(t / t_{b c}\right)_{s}$ of each case relative to that of the base case. This value can be compared between each configuration and the base case defined as:

$$
\begin{aligned}
\left(t / t_{b c}\right)_{m} & =\frac{t_{m}}{t_{m, b c}} \\
\left(t / t_{b c}\right)_{s} & =\frac{t_{s}}{t_{s, b c}}
\end{aligned}
$$

The magnitude of the time ratio indicates the percentage of time in which a particular configuration melts or solidifies relative to the non-enhanced PCM case.

\subsection{Temperature distribution in the PCM}

Measured local temperatures are presented in Fig. 2 through Fig. 4. In these figures, the open and filled symbols represent the temperatures at a radius of $r_{1}=9 \mathrm{~mm}$ and $r_{2}=15 \mathrm{~mm}$, respectively. The 
dashed line represents the HP temperature at $z=55 \mathrm{~mm}$, and the solid line represents the average temperature of two thermocouple measurements on the copper disc at $\theta_{1}=0^{\circ}$ and $\theta_{3}=180^{\circ}$ on the $\mathrm{PCM}$ side at $r=12 \mathrm{~mm}$. During melting with $\alpha=0^{\circ}$ and for all cases of solidification, a high degree of symmetry was observed about the centerline of the tube. Therefore, each symbol in Fig. 2 and Fig. 3 represents the average temperature of three thermocouple measurements at $\theta_{1}=0^{\circ}, \theta_{2}=90^{\circ}$ and $\theta_{3}=180^{\circ}$ with the same $r$ and $z$.

The temperature distribution during solidification $\left(\alpha=0^{\circ}\right)$ is presented for the Foam-PCM, HPPCM and HP-Foam-PCM cases in Fig. 2. The Foam-PCM configuration in Fig. 2 (a) corresponds to a one-dimensional solidification front that advances axially from the copper disc, as indicated by the similar temperatures at the inner and outer radii locations at the same axial location. In the HP-PCM case, the HP acts to increase the available heat transfer surface area in contact with the PCM as observed by the similar temperatures of the HP and copper disc in Fig. 2 (b). The effect of heat transfer through the copper disc is observed by solidification occurring at $\left(z_{1}=15 \mathrm{~mm}, r_{2}=15 \mathrm{~mm}\right)$ (square symbols) before the other axial locations. However, heat transfer through the HP is shown to be dominant as the last two locations that experience solidification are located at different axial locations, yet, solidify at a similar time. When foam is added onto the HP for the HP-Foam-PCM configuration in Fig. 2 (c), a similar solidification phenomenon is observed as for the HP-PCM case, except that the higher thermal conductivity of the enhancer-PCM composite results in a faster solidification rate.

Representative temperature histories during melting for the Foam-PCM, HP-PCM and HP-FoilPCM cases with $\alpha=0^{\circ}$ are presented in Fig. 3. The Foam-PCM case exhibits a one-dimensional melting front that advances axially from the copper disc, as seen in Fig. 3 (a). Natural convection heat transfer for the HP-PCM case is inferred from Fig. 3 (b) since the uppermost thermocouple locations (circles) melt prior to those at the mid-height locations (triangles); especially since melting occurs at $\left(r_{2}=15 \mathrm{~mm}, z_{3}=\right.$ $45 \mathrm{~mm}$ ) prior to $\left(r_{1}=9 \mathrm{~mm}, z_{2}=30 \mathrm{~mm}\right)$. For the HP-Foam-PCM case, a conduction-dominated melting process is inferred from the temperature distribution in Fig. 3 (c). Natural convection is suppressed in the foam, since the thermocouple locations infer melting with increasing axial and radial locations rather than 
the uppermost thermocouple locations melting prior to the lower locations. The combination of the HP with foam allows for the HP to transfer heat further into the PCM which is then dispersed in a conduction-dominated manner within the foam-PCM composite.

In Fig. 2 and Fig. 3 with $\alpha=0^{\circ}$, the average values for each $(r, z)$ position are displayed since symmetry about the central axis was present. However, when $\alpha=90^{\circ}$, three-dimensional melting occurs. In Fig. 4, the temperature distribution for the HP-Foil-PCM (left) and HP-Foam-PCM (right) cases with $\alpha$ $=90^{\circ}$ are presented at (a) $z_{1}=15 \mathrm{~mm}$, (b) $z_{2}=30 \mathrm{~mm}$ and (c) $z_{3}=45 \mathrm{~mm}$.

In Fig. 4, a few key distinctions can be noted for both configurations. First, the overall temperature difference within the PCM is approximately $3{ }^{\circ} \mathrm{C}$ for the HP-Foil-PCM case, while it may be greater than $10{ }^{\circ} \mathrm{C}$ for the HP-Foam-PCM case. Another feature can be noted by comparing the solid and dashed lines that represent the temperature of the copper disc and the HP within the PCM, respectively. These values are similar for the HP-Foam-PCM case with the temperature of the copper disc being slightly less (within $1{ }^{\circ} \mathrm{C}$ after the first $10 \mathrm{~min}$ ) than the HP temperature in the PCM, indicating a greater amount of heat transfer from the disc. Yet, for the HP-Foil-PCM configuration the opposite is observed, indicating higher heat transfer through the HP. Also, the order in which each $(r, z)$ location surpasses the melting temperature indicates that heat transfer through the HP is dominant relative to the disc for the HPFoil-PCM configuration.

As mentioned previously, there are two distinct methods in which heat transfer rates are improved for PCM systems that consist of increasing thermal penetration or thermal diffusion. By combining a HP with foils or foam, heat transfer rates are shown to be further improved relative to each enhancement individually. Since solidification is mainly conduction-dominated, orientation is rather insignificant, however, orientation may significantly affect melting due to varying natural convection flows. However, inclusion of metal enhancers, such as foils or foam, may significantly suppress natural convection which will desensitize the melting to changes in the test cell orientation. 


\subsection{Photographic observations}

The influence of system inclination during melting is investigated in this section for the HP-PCM, Rod-PCM and non-enhanced PCM configurations. Each photograph is taken from the right side view as indicated in Fig. 1 (b) and is parallel to the cross section view containing the plane of symmetry of Fig. 1 (a). It should be noted that the silicone that was used to seal and secure the thermocouples at $\theta_{2}=90^{\circ}$ on the back of the acrylic tube appears white in each photograph. Also, the aluminum tape utilized to secure the thermocouples to the HP after the application of the thermal epoxy also appears in the photographs at the tip and base of the HP and rod. The solid-liquid interface is easily discernible in most of the photographs.

Photographs during solidification for the (a) HP-PCM, (b) Rod-PCM and (c) non-enhanced PCM cases at $t=15 \mathrm{~min}$ (left) and $t=30 \mathrm{~min}$ (right) with $\alpha=0^{\circ}$ are shown in Fig. 5. Orientation has minimal influence during solidification, therefore, only the vertical orientation is presented for brevity. The solidification front which advances from the copper base is similar for each case, which indicates a similar degree of heat transfer. Therefore, the increase in heat transfer surface area by adding the HP or rod, results in a larger mass of solidified PCM relative to the non-enhanced PCM case at any time. It can also be seen that the HP performance is superior to that of the rod due to the larger, more uniform radius of solid PCM at all axial distances for the HP in Fig. 5 (a), while the rod has a conical shape that decreases in diameter at increasing axial locations in Fig. 5 (b). As time progresses from $t=15$ min (left) to $t=30 \mathrm{~min}$ (right), the solidification fronts advance as expected.

Photographs during melting are presented in Fig. 6 for the (a) HP-PCM, (b) Rod-PCM and (c) non-enhanced PCM configurations at $t=60$ min with $\alpha=0^{\circ}$ (left) and $\alpha=90^{\circ}$ (right). The inclination angle is shown to influence the shape of the solid-liquid interface in each case due to the complex threedimensional natural convection effects. The effect of symmetry about the center of the tube is seen for the vertical cases, however, for all non-vertical cases, only symmetry about the plane of Fig. 1 (a) is observed. It is interesting to note that the solid-liquid interfaces closest to the copper disc is similar for the Rod-PCM and non-enhanced PCM cases with $\alpha=0^{\circ}$ and $\alpha=90^{\circ}$ in Fig. 6. Inclusion of the HP or rod 
increases the rate of melting by increasing the overall heat transfer surface area in contact with the PCM. Obviously, melting occurs around the periphery of the HP or rod, however, the solid-liquid interface is not able to be observed. It should also be noted that constrained melting is present in this study, in which the solid PCM remains fixed (due to the presence of thermocouples in the PCM) and does not fall to the bottom of the enclosure, as evident in Fig. 6 (left). In general, the addition of the HP or rod allows for natural convection to provide an additional downward melting front relative to the non-enhanced case which may be seen in the photographs.

System inclination is shown to affect the melting process in the HP-PCM configuration in Fig. 7. For each case, natural convection significantly alters the solid-liquid interfaces. The accumulation of warmer PCM at the top of the enclosure results in an additional downward melting front. For $\alpha=0^{\circ}$ (left), melting is symmetric about the center of the HP, as observed by the similar axial height of each upper and lower solid liquid interface, while for all other inclination angles only plane symmetry is observed about the cross section seen in Fig. 1 (a). Each orientation is characterized by a unique three-dimensional solidliquid interface.

The photographic observations reveal that at $t=90 \mathrm{~min}$, the $\alpha=90^{\circ}$ case is the only orientation with solid PCM remaining. Furthermore, the location of the solid PCM is at the bottom of the horizontal cylinder, which is not effectively melted by either the HP or copper disc since natural buoyancy causes the warmer PCM to accumulate at the top of the system. However, for all other cases the copper disc resides below the PCM, to some extent, which allows for natural convection to aid in the melting process.

\subsection{Liquid fraction histories}

While temperature histories and photographs aid the explanation of the physical phenomena that occurs during phase change, they cannot provide detailed information as to the amount of PCM which has melted or solidified. Hence the need to determine the liquid fraction histories since they can be related to the stored latent energy. 
The effects of system inclination and heat transfer through the copper disc during solidification and melting for the HP-PCM configuration with $|\Delta T|=17^{\circ} \mathrm{C}$ are presented in Fig. 8. As expected, the conduction-dominated solidification process yields similar liquid fraction histories regardless of orientation, with an average variation in liquid fraction of less than $\Delta f_{l}=0.03$. Heat transfer through the copper disc decreased the average time for $95 \%$ complete solidification (for each $\alpha$ ) from $t_{s}=112 \mathrm{~min}$ with an acrylic disc to $t_{s}=82$ min with a copper disc.

However, during melting, natural convection may significantly change the melting rates depending on the respective locations of the heated base and solid PCM. With heat transfer through a copper disc (open symbols), the liquid fraction with $\alpha=90^{\circ}$ reached a liquid fraction that was approximately $\Delta f_{l}=0.09$ higher than with $\alpha=0^{\circ}$ until all the solid PCM remained below the horizontal HP. Also note that for $\alpha=30^{\circ}$ and $\alpha=60^{\circ}$, the liquid fraction histories lie between the two extreme cases with $\alpha=0^{\circ}$ and $\alpha=90^{\circ}$. Therefore, the cases with $\alpha=30^{\circ}$ and $\alpha=60^{\circ}$ will not be discussed further.

When the copper disc was replaced with an acrylic disc to minimize heat transfer, the liquid fraction with $\alpha=90^{\circ}$ was higher than with $\alpha=0^{\circ}$ by a value of $\Delta f_{l}=0.20$ (filled symbols) as seen in Fig. 8. Therefore, when the amount of heat transfer through the medium securing the HP, such as a plate or tube, is small relative to that through the HP, the horizontal orientation may be more beneficial than a vertical orientation. This may occur as the length of the HP increases. However, as the HP length increases, the demand on the HP wick to return the liquid working fluid back to the HP evaporator also increases. Hence, it may be desirable to slightly incline a bare HP with respect to the horizontal in order to maintain the improved natural convection heat transfer yet also provide a sufficient amount of HP condensate to the HP evaporator.

By comparing the HP-PCM cases during melting in Fig. 8 (b), the case with the copper disc achieves a liquid fraction that is higher than that with an acrylic disc by approximately $\Delta f_{l}=0.35$ with $\alpha=$ $0^{\circ}$ and $\Delta f_{l}=0.12$ with $\alpha=90^{\circ}$ at the time corresponding to $f_{l}=0.80$. Hence, the effect of heat transfer through the copper disc during melting is more significant for the vertical case compared to the horizontal case. 
In Fig. 9, the liquid fraction histories during solidification for the HP-Foil-PCM, HP-Foam-PCM, HP-PCM, Rod-PCM, Foam-PCM and non-enhanced PCM cases with vertical and horizontal orientations are presented. The effect of driving temperature between the HTF and PCM is investigated with the triangle, square and circle symbols representing values of $8{ }^{\circ} \mathrm{C}, 17^{\circ} \mathrm{C}$ and $25^{\circ} \mathrm{C}$, respectively. The filled and open symbols for each driving temperature represent the vertical $\left(\alpha=0^{\circ}\right)$ and horizontal $\left(\alpha=90^{\circ}\right)$ orientations, respectively.

The results reveal that nearly all cases behave similarly, with the solidification rate decreasing with time due to the steadily increasing distance between the heat transfer surfaces (disc and HP or rod) and the solid-liquid interface. Therefore, the overall solidification rate is not a robust figure of merit since the liquid fraction histories are not linear. For the most part, the effect of orientation is negligible during solidification except for the HP-Foil-PCM case with $|\Delta T|=17^{\circ} \mathrm{C}$ and $|\Delta T|=25^{\circ} \mathrm{C}$. This variation in the liquid fraction histories may be attributed to the performance of the HP, mainly its orientation and heat transfer throughput. For all other configurations and driving temperatures, the liquid fraction histories are similar which may be explained by the conduction-dominated nature of solidification.

During solidification in the HP-Foil-PCM configuration with $\alpha=0^{\circ}$, the HP evaporator is situated above its condenser which causes the capillary forces within the wick to act in opposition to gravity. Yet, when the HP is horizontally oriented with $\alpha=90^{\circ}$, these forces do not act in opposition to each other and the system performance is improved by approximately $\Delta f_{l}=0.09$ with $|\Delta T|=25^{\circ} \mathrm{C}$ and $\Delta f_{l}=0.07$ with $|\Delta T|=17^{\circ} \mathrm{C}$ relative to the $\alpha=0^{\circ}$ case. Also, as $|\Delta T|$ increases, the heat transfer rates within the system increase which may ultimately lead to the capillary limit of the HP being approached with $\alpha=0^{\circ}$.

In Fig. 10, the liquid fraction histories during melting may be observed for each configuration. The results indicate that the orientation affects the melting process to a greater degree than during solidification, except for the two HP-Foil-PCM cases mentioned previously. For the HP-Foil-PCM and HP-Foam-PCM configurations, a slightly higher liquid fraction of $\Delta f_{l}=0.03$ and $\Delta f_{l}=0.05$, respectively, is observed with $\alpha=0^{\circ}$ compared to $\alpha=90^{\circ}$ which is a result of the gravity assisted HP operation with $\alpha$ $=0^{\circ}$ as the HP evaporator is situated below its condenser. Since the rod has similar exterior dimensions as 
the HP, a similar melting phenomenon is observed and will not be repeated here. Yet, an improved performance is obtained with the HP compared to the rod by its superior thermal transport properties. Orientation is not observed to significantly affect the Foam-PCM configuration since the foam suppresses natural convection. In Fig. 10 (f), natural convection is observed to be beneficial in a non-enhanced system with $\alpha=0^{\circ}$ since the heated disc is positioned below the PCM. For each system during melting, an increase in $|\Delta T|$ results in an increase in the melting rates.

\subsection{Performance comparison for each heat transfer enhancement technique}

The liquid fraction histories for each configuration are presented for $\alpha=0^{\circ}$ and $\alpha=90^{\circ}$ in Fig. 11 with $|\Delta T|=17^{\circ} \mathrm{C}$. For the conditions considered here, examination of Fig. 11 reveals that the degree of enhancement can be separated into three main subdivisions: (i) non-enhanced, (ii) single enhancement and (iii) combined enhancement. The inherent need for a heat transfer enhancement technique in PCM systems can be seen for the non-enhanced PCM configuration, particularly for solidification. When either a HP, rod or foam is implemented to increase heat transfer rates, phase change occurs faster with the highest performance for the HP-PCM configuration. When the HP was combined with the foils or foam, the degree of enhancement can be further increased by a considerable amount.

While similar conclusions were reported in [26] for a vertical configuration, the Foam-PCM and non-enhanced PCM configurations as well as the effects of system orientation and base heat transfer are also considered here. The liquid fraction histories for the Foam-PCM configuration are shown to be similar to the Rod-PCM configuration in Fig. 11. Therefore, the contribution of foam on the enhancement in melting rates is not as significant as reported by others which may be attributed to the larger length scale than many which have been studied previously. It is interesting to note that a similar liquid fraction histories are obtained for the HP-PCM, Rod-PCM and Foam-PCM cases with $\alpha=90^{\circ}$ with an average variation of about $\Delta f_{l}=0.05$ during melting.

In general the effect of heat transfer through the copper disc is more significant for the HP-FoamPCM configuration relative to the HP-Foil-PCM configuration with $\alpha=0^{\circ}$. This is attributed to the 
orientation of the foils being parallel to the disc resulting in highly two-dimensional $(r, \theta)$ heat transfer, while the foam is more accommodating to three-dimensional heat transfer from both the base and HP. During the initial 5 min of operation, especially for $|\Delta T|=25^{\circ} \mathrm{C}$ in Fig. 10 at $\alpha=0^{\circ}$ (filled circles), the HP-Foam-PCM configuration has a higher liquid fraction than the HP-Foil-PCM configuration with the same driving temperature and orientation. This may be attributed to either superior operation of the HP in the vertical orientation as discussed previously, or that natural convection within the foam is somewhat significant at the onset of melting which decreases shortly due to the high flow resistance within the foam.

\subsection{Average melting rates}

As previously mentioned, the solidification rates do not merit comparison between distinct cases since the liquid fraction histories are not linear, as observed in Fig. 9. On the other hand, the liquid fraction histories during melting with $\alpha=0^{\circ}$, and melting rates for the HP-Foil-PCM, HP-Foam-PCM and non-enhanced PCM configurations with $\alpha=90^{\circ}$ are fairly linear up to $f_{l}=0.95$. These melting rates are calculated with Eq. (4) and the results are summarized in Table 2. It may be seen that the melting rates for the HP-Foil-PCM cases are 8.5 and 9.5 times that of the non-enhanced PCM cases with $\alpha=0^{\circ}$ and $\alpha=$ $90^{\circ}$, respectively.

\subsection{Effectiveness at $95 \%$ complete phase change}

The effectiveness $\left(\varepsilon_{m}\right.$ and $\left.\varepsilon_{s}\right)$ is presented at the time of $95 \%$ complete phase change $\left(t_{m}\right.$ and $\left.t_{s}\right)$ in Table 2, as well as Fig. 12 (circle symbols). The highest effectiveness is achieved for the HP-Foil-PCM configuration with a value of 5.7 and $11.9\left(5.3\right.$ and 9.4) with $\alpha=0^{\circ}\left(\alpha=90^{\circ}\right)$ during melting and solidification, respectively. Therefore, the combination of the HP and foils are approximately $70 \%, 370$ $\%, 450 \%$ and $670 \%(45 \%, 150 \%, 180 \%$ and $220 \%)$ more effective during melting (solidification) for each orientation than the HP-Foam-PCM, HP-PCM, Rod-PCM and Foam-PCM configurations, respectively.

The effectiveness during melting is seen to be considerably larger than during solidification and can be understood by examining Eqs. (2) and (3) along with Fig. 11. The liquid fraction for the non- 
enhanced PCM configuration during melting is much lower than during solidification since it is initially conduction-dominated and the liquid PCM has a lower thermal conductivity. For example, the liquid fraction for the HP-Foil-PCM and non-enhanced PCM configurations with $\alpha=0^{\circ}$ during solidification (melting) is approximately 0.05 and $0.80(0.95$ and 0.08$)$ at $t=13 \min (t=16 \mathrm{~min})$, respectively. Hence, the solidification and melting effectiveness is 5.7 and 11.9, respectively, for the HP-Foil-PCM configuration with $\alpha=0^{\circ}$ and $|\Delta T|=17^{\circ} \mathrm{C}$. Note that the largest error bars are encountered for the effectiveness of the HP-Foil-PCM cases, since its value is highly sensitive to the value of the liquid fraction for the non-enhanced case. Therefore, the time ratio for phase change is introduced in the following section to provide a relative measure of performance between each case and the non-enhanced case with minimal uncertainty.

\subsection{Time ratio for complete phase change}

An additional figure of merit to compare distinct cases is the ratio of times for each case to reach $95 \%$ phase change $\left(t_{m}, t_{s}\right)$ relative to that of the non-enhanced PCM case defined in Eqs. (5) and (6). In Fig. 12, the filled square symbols denote the time ratio during melting $\left(t / t_{b c}\right)_{m}$ and solidification $\left(t / t_{b c}\right)_{s}$ with $|\Delta T|=17^{\circ} \mathrm{C}$ for each case. The figure shows that $\left(t / t_{b c}\right)_{m}$ and $\left(t / t_{b c}\right)_{s}$ are approximately 0.11 and 0.03 for the HP-Foil-PCM case regardless of orientation. Therefore, the complete melting and solidification times for the HP-Foil-PCM configuration are approximately $11 \%$ and $3 \%$ of the total time for the nonenhanced PCM (HP-PCM) configuration, respectively. The time for complete melting and solidification for each case may be seen in Table 2 .

\section{Conclusions}

Experiments were conducted to investigate the effect of system inclination angle for a cylindrical PCM system with heat transfer through both an underlying copper disc and a HP or rod, while the HP was further enhanced with aluminum foam or foils. Measured liquid fractions, temperature distributions and photographs are presented to analyze both melting and solidification. A total of 6 configurations and 28 case studies were investigated with varying orientation and driving temperatures. Orientation had a 
minimal effect on the solidification process due to conduction-dominated heat transfer, with the exception of the HP-Foil-PCM configuration. The variation in performance for the HP-Foil-PCM configuration due to orientation was dependent on the internal operation of the HP, in which a capillary limit was most likely being approached. This variation is due to the HP evaporator being positioned above its condenser during solidification with $\alpha=0^{\circ}$, which increases with an increase in the heat transfer throughput.

During melting for the HP-PCM, Rod-PCM and non-enhanced PCM configurations, the change in natural convection transfer with orientation may significantly alter the melting rates. A notable finding for the HP-PCM and Rod-PCM configurations is that the liquid fraction in a horizontal case was increased by $\Delta f_{l}=0.09\left(\Delta f_{l}=0.20\right)$ relative to a vertical case with (without) heat transfer through the copper disc until the remaining solid PCM resided below the horizontal HP or rod.

For the HP-Foil-PCM and HP-Foam-PCM configurations, the average variation in liquid fraction between the vertical and horizontal orientations is $\Delta f_{l}=0.03$ and $\Delta f_{l}=0.05\left(\Delta f_{l}=0.07\right.$ and $\left.\Delta f_{l}=0.01\right)$ during melting (solidification), respectively, with $|\Delta T|=17^{\circ} \mathrm{C}$. This variation is mostly attributed to the operation of the HP, which is preferred to be vertical to allow gravity to assist in the return of the internal HP working fluid to the HP evaporator. However, when the complete melting and solidification times of each configuration are considered, the minor variation in the liquid fraction histories for the $\alpha=0^{\circ}$ and $\alpha$ $=90^{\circ}$ cases for the HP-Foil-PCM and HP-Foam-PCM configurations are outweighed by the improvement in performance for the combined enhancement techniques relative to the other systems. Therefore, these combinations promising heat transfer enhancement methods for use in LHTES systems. In this study, the HP-Foil-PCM configuration with $\varphi=0.945$ and $|\Delta T|=17^{\circ} \mathrm{C}$ was capable of increasing the melting rates by about 9 times and reducing the total solidification and melting times to about $3 \%$ and $12 \%$ percent that of the non-enhanced PCM configuration regardless of orientation.

\section{Acknowledgements}

This work was supported by contracts from Boeing and the U.S. Department of Energy. 


\section{References}

[1] C.W. Robak, T.L. Bergman, A. Faghri, Economic evaluation of latent heat thermal energy storage using embedded thermosyphons for concentrating solar power applications, Solar Energy 85 (10) (2011) 2461-2473.

[2] F. Agyenim, N. Hewitt, P. Eames, M. Smyth, A review of materials, heat transfer and phase change problem formulation for latent heat thermal energy storage systems (LHTESS), Renewable and Sustainable Energy Reviews 14 (2) (2010) 615-628.

[3] A.A. Al-Abidi, S. Mat, K. Sopian, M.Y. Sulaiman, A.T. Mohammad, Numerical study of PCM solidification in a triplex tube heat exchanger with internal and external fins, International Journal of Heat and Mass Transfer 61 (2013) 684-695.

[4] N. Sharifi, T.L. Bergman, A. Faghri, Enhancement of PCM melting in enclosures with horizontally-finned internal surfaces, International Journal of Heat and Mass Transfer 54 (19-20) (2011) 4182-4192.

[5] M. Sugawara, Y. Komatsu, Y. Takahashi, H. Beer, Freezing enhancement around a horizontal tube using copper foil disks, Heat and Mass Transfer 47 (12) (2011) 1691-1698.

[6] C. Alkan, A. Sarı, A. Karaipekli, Preparation, thermal properties and thermal reliability of microencapsulated n-eicosane as novel phase change material for thermal energy storage, Energy Conversion and Management 52 (1) (2011) 687-692.

[7] N. Calvet, X. Py, R. Olivès, J.-P. Bédécarrats, J.-P. Dumas, F. Jay, Enhanced performances of macro-encapsulated phase change materials (PCMs) by intensification of the internal effective thermal conductivity, Energy 55 (2013) 956-964.

[8] C.J. Ho, J.Y. Gao, Preparation and thermophysical properties of nanoparticle-in-paraffin emulsion as phase change material, International Communication in Heat and Mass Transfer 36 (15) (2009) $467-470$.

[9] Y. Tian, C.Y. Zhao, Thermal and exergetic analysis of metal foam-enhanced cascaded thermal energy storage (MF-CTES), International Journal of Heat and Mass Transfer 58 (1-2) (2013) 8696.

[10] C.W. Robak, T.L. Bergman, A. Faghri, Enhancement of latent heat energy storage using embedded heat pipes, International Journal of Heat and Mass Transfer 54 (15-16) (2011) 34763484.

[11] N. Sharifi, S. Wang, T.L. Bergman, A. Faghri, Heat pipe-assisted melting of a phase change material, International Journal of Heat and Mass Transfer 55 (13-14) (2012) 3458-3469.

[12] A. Faghri, Thermal Energy Storage Heat Exchanger, US Patent No. 4976308, 1990.

[13] A. Faghri, Micro Heat Pipe Energy Storage System, US Patent No. 5000252, 1991.

[14] A. Faghri, Heat Pipe Science and Technology, Taylor \& Francis Group, Washington, D.C., 1995. 
[15] X. Gui, D. Tang, S. Liang, X. Yuan, Influence of radial thickness of phase change material on thermal performance of heat pipe receiver under microgravity, Heat Transfer Engineering 34 (7) (2013) 608-616.

[16] H. Shabgard, T.L. Bergman, N. Sharifi, A. Faghri, High temperature latent heat thermal energy storage using heat pipes, International Journal of Heat and Mass Transfer 53 (15-16) (2010) 29792988.

[17] H. Shabgard, C.W. Robak, T.L. Bergman, A. Faghri, Heat transfer and exergy analysis of cascaded latent heat storage with gravity-assisted heat pipes for concentrating solar power applications, Solar Energy 86 (3) (2012) 816-830.

[18] Z. Liu, Z. Wang, C. Ma, An experimental study on the heat transfer characteristics of a heat pipe heat exchanger with latent heat storage. Part II: Simultaneous charging/discharging modes, Energy Conversion and Management 47 (7-8) (2006) 967-991.

[19] C.Y. Zhao, W. Lu, Y. Tian, Heat transfer enhancement for thermal energy storage using metal foams embedded within phase change materials (PCMs), Solar Energy 84 (8) (2010) 1402-1412.

[20] K. Lafdi, O. Mesalhy, S. Shaikh, The effect of surface energy on the heat transfer enhancement of paraffin wax/carbon foam composites, Carbon 45 (11) (2007) 2188-2194.

[21] O. Mesalhy, K. Lafdi, A. Elgafy, Carbon foam matrices saturated with PCM for thermal protection purposes, Carbon 44 (10) (2006) 2080-2088.

[22] Z.G. Qu, W.Q. Li, J.L. Wang, W.Q. Tao, Passive thermal management using metal foam saturated with phase change material in a heat sink, International Communication in Heat and Mass Transfer 39 (10) (2012) 1546-1549.

[23] S.-T. Hong, D.R. Herling, Open-cell aluminum foams filled with phase change materials as compact heat sinks, Scripta Materialia 55 (10) (2006) 887-890.

[24] W.Q. Li, Z.G. Qu, Y.L. He, W.Q. Tao, Experimental and numerical studies on melting phase change heat transfer in open-cell metallic foams filled with paraffin, Applied Thermal Engineering 37 (2012) 1-9.

[25] N. Sharifi, A. Faghri, T.L. Bergman, M.J. Allen, Melting and solidification enhancement using heat pipe with foils, International Journal of Heat and Mass Transfer 78 (2014) 930-941.

[26] M.J. Allen, T.L. Bergman, A. Faghri, N. Sharifi, Robust heat transfer enhancement during melting and solidification of a pcm using a combined heat pipe-metal foam or foil configuration, Journal of Heat Transfer (2014) Submitted.

[27] C.E. Andraka, K.S. Rawlinson, N.P. Siegel, Technical feasibility of storage on large dish Stirling systems, Sandia National Laboratories, Albuquerque, NM, Report No. SAND2012-8352 (2012).

[28] H. Shabgard, A. Faghri, T.L. Bergman, C.E. Andraka, Numerical simulation of heat pipe-assisted latent heat thermal energy storage unit for dish-stirling systems, Journal of Solar Energy Engineering 136 (2) (2014) 021025-1-12. 
[29] W.-B. Ye, D.-S. Zhu, N. Wang, Effect of the inclination angles on thermal energy storage in a quadrantal cavity, Journal of Thermal Analysis and Calorimetry 110 (3) (2012) 1487-1492.

[30] B. Kamkari, H. Shokouhmand, F. Bruno, Experimental investigation of the effect of inclination angle on convection-driven melting of phase change material in a rectangular enclosure, International Journal of Heat and Mass Transfer 72 (2014) 186-200.

[31] N. Sharifi, C.W. Robak, T.L. Bergman, A. Faghri, Three-dimensional PCM melting in a vertical cylindrical enclosure including the effects of tilting, Intenational Journal of Heat and Mass Transfer 65 (2013) 798-806.

[32] A. Hasan, Phase change material energy storage system employing palmitic acid, Solar Energy 52 (2) (1994) 1994.

[33] K. Sasaguchi, A. Ishihara, H. Zhang, Numerical study on utilization of melting of phase change material for cooling of a heated surface at a constant rate, Numerical Heat Transfer Part-A Application 29 (1) (1996) 19-31.

[34] B.W. Webb, R. Viskanta, Natural-convection dominated melting heat transfer in an inclined rectangular enclosure, International Journal of Heat and Mass Transfer 29 (2) (1986) 183-192.

[35] K. Nithyanandam, R. Pitchumani, Computational modeling of latent thermal energy storage system with embedded heat pipes, International Mechanical Engineering Congress and Expoition, (2010) 369-376.

[36] K. Nithyanandam, R. Pitchumani, Computational studies on a latent thermal energy storage system with integral heat pipes for concentrating solar power, Applied Energy 103 (2013) 400 415.

[37] K. Nithyanandam, R. Pitchumani, Analysis and optimization of a latent thermal energy storage system with embedded heat pipes, International Journal of Heat and Mass Transfer 54 (21-22) (2011) 4596-4610.

[38] K. Nithyanandam, R. Pitchumani, Thermal energy storage with heat transfer augmentation using thermosyphons, International Journal of Heat and Mass Transfer 67 (2013) 281-294.

[39] Omega, Epoxies and Thermal Conductive Pastes, (2013).

[40] R.S. Figliola, D.E. Beasley, Theory and Design for Mechanical Measurements, fourth ed., Wiley, Hoboken, 2006. 


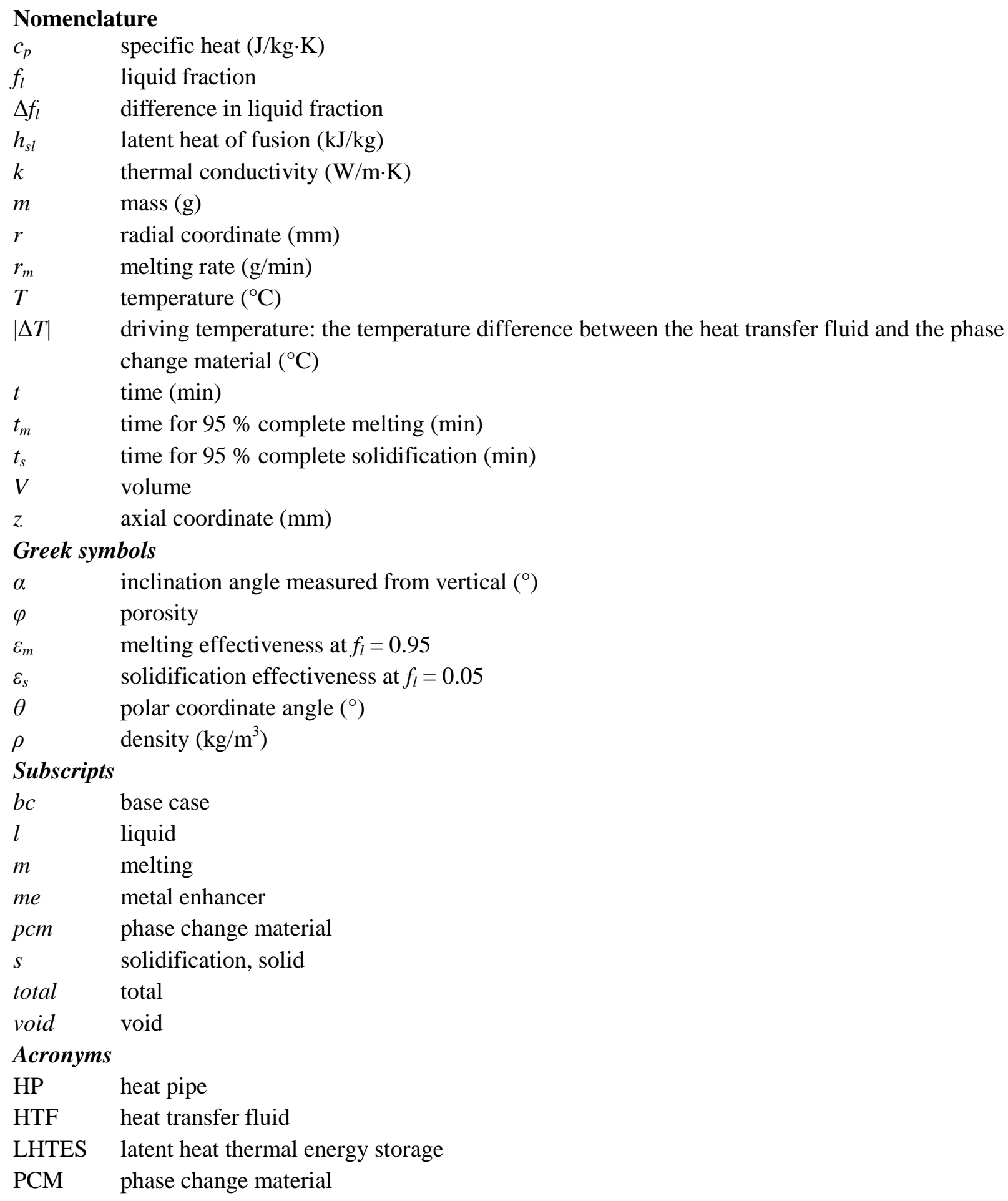




\section{List of Tables}

Table 1. Thermophysical properties of n-octadecane at $T=301.5 \mathrm{~K}$ [10].

Table 2. Time, effectiveness and melting rates for $95 \%$ complete phase change (min). 
Table 1. Thermophysical properties of n-octadecane at $T=301.5 \mathrm{~K}$ [10].

\begin{tabular}{ll}
\hline Parameter & Value \\
\hline Melting point, $T_{m}[\mathrm{~K}]$ & 301 \\
Latent heat of fusion, $h_{s l}[\mathrm{~kJ} / \mathrm{kg}]$ & 243.5 \\
Liquid thermal conductivity, $k_{l}[\mathrm{~W} / \mathrm{m} \cdot \mathrm{K}]$ & 0.148 \\
Solid thermal conductivity, $k_{s}[\mathrm{~W} / \mathrm{m} \cdot \mathrm{K}]$ & 0.358 \\
Liquid density, $\rho_{l}\left[\mathrm{~kg} / \mathrm{m}^{3}\right]$ & 770 \\
Solid density, $\rho_{s}\left[\mathrm{~kg} / \mathrm{m}^{3}\right]$ & 800 \\
Liquid specific heat, $c_{p, l}[\mathrm{~J} / \mathrm{kg} \cdot \mathrm{K}]$ & 2160 \\
Solid specific heat, $c_{p, s}[\mathrm{~J} / \mathrm{kg} \cdot \mathrm{K}]$ & 1912 \\
\hline
\end{tabular}


Table 2. Time, effectiveness and melting rates for $95 \%$ complete phase change (min).

\begin{tabular}{|c|c|c|c|c|c|c|c|c|c|c|c|}
\hline \multirow[t]{2}{*}{ Configuration } & \multirow[t]{2}{*}{$|\Delta T|$} & \multicolumn{2}{|c|}{$t_{s}(\mathrm{~min})$} & \multicolumn{2}{|c|}{$\varepsilon_{s}$} & \multicolumn{2}{|c|}{$t_{m}(\min )$} & \multicolumn{2}{|c|}{$\varepsilon_{m}$} & \multicolumn{2}{|c|}{$r_{m}(\mathrm{~g} / \mathrm{min})$} \\
\hline & & $\alpha=\mathbf{0}^{\circ}$ & $\alpha=90^{\circ}$ & $\alpha=\mathbf{0}^{\circ}$ & $\alpha=90^{\circ}$ & $\alpha=0^{\circ}$ & $\alpha=90^{\circ}$ & $\alpha=\mathbf{0}^{\circ}$ & $\alpha=90^{\circ}$ & $\alpha=\mathbf{0}^{\circ}$ & $\alpha=90^{\circ}$ \\
\hline HP-Foil-PCM & $8^{\circ} \mathrm{C}$ & 21 & 23 & - & - & 30 & 34 & - & - & 2.00 & 1.76 \\
\hline HP-Foil-PCM & $17{ }^{\circ} \mathrm{C}$ & 13 & 11 & 5.7 & 5.3 & 16 & 18 & 11.9 & 9.4 & 3.75 & 3.33 \\
\hline HP-Foil-PCM & $25^{\circ} \mathrm{C}$ & 13 & 9 & - & - & 12 & 14 & - & - & 5.00 & 4.29 \\
\hline HP-Foam-PCM & $17^{\circ} \mathrm{C}$ & 26 & 28 & 3.7 & 3.8 & 34 & 38 & 7.2 & 5.4 & 1.76 & 1.58 \\
\hline HP-Foam-PCM & $25^{\circ} \mathrm{C}$ & 22 & 20 & - & - & 22 & 24 & - & - & 2.73 & 2.50 \\
\hline HP-PCM & $8^{\circ} \mathrm{C}$ & 164 & 168 & - & - & 204 & 244 & - & - & 0.29 & - \\
\hline HP-PCM & $17^{\circ} \mathrm{C}$ & 84 & 72 & 2.3 & 2.1 & 78 & 106 & 2.2 & 2.3 & 0.77 & - \\
\hline HP-PCM & $25^{\circ} \mathrm{C}$ & 72 & 70 & - & - & 56 & 74 & - & - & 1.07 & - \\
\hline Rod-PCM & $17^{\circ} \mathrm{C}$ & 102 & 98 & 1.9 & 2.0 & 96 & 118 & 2.0 & 1.9 & 0.63 & - \\
\hline Foam-PCM & $17^{\circ} \mathrm{C}$ & 112 & 112 & 1.7 & 1.7 & 106 & 104 & 1.3 & 1.5 & 0.57 & - \\
\hline Non-enhanced & $17^{\circ} \mathrm{C}$ & 398 & 428 & 1.0 & 1.0 & 136 & 172 & 1.0 & 1.0 & 0.44 & 0.35 \\
\hline
\end{tabular}




\section{List of Figures}

Fig. 1. Schematic of the experimental apparatus (a) central cross section parallel to the right side view (plane of symmetry) and (b) top view.

Fig. 2. Temperature distribution during solidification with $\alpha=0^{\circ}$ and $|\Delta T|=17^{\circ} \mathrm{C}$ for the (a) Foam-PCM, (b) HP-PCM and (c) HP-Foam-PCM configurations.

Fig. 3. Temperature distribution during melting with $\alpha=0^{\circ}$ and $|\Delta T|=17^{\circ} \mathrm{C}$ for the (a) Foam-PCM, (b) HP-PCM and (c) HP-Foam-PCM configurations.

Fig. 4. Temperature distribution during melting for the HP-Foil-PCM (left) and HP-Foam-PCM (right) configurations with $|\Delta T|=17^{\circ} \mathrm{C}$ and $\alpha=90^{\circ}$ for (a) $z_{1}=15 \mathrm{~mm}$ (b) $z_{2}=30 \mathrm{~mm}$ and (c) $z_{3}=45 \mathrm{~mm}$. Fig. 5. Photographs during solidification with $\alpha=0^{\circ}$ and $|\Delta T|=17^{\circ} \mathrm{C}$ for the (a) HP-PCM, (b) Rod-PCM and (c) non-enhanced PCM configurations at $t=15 \mathrm{~min}$ (left) and $t=30 \mathrm{~min}$ (right).

Fig. 6. Photographs during melting at $t=60$ min with $\alpha=0^{\circ}$ (left), $\alpha=90^{\circ}$ (right) and $|\Delta T|=17^{\circ} \mathrm{C}$ for the (a) HP-PCM, (b) Rod-PCM and (c) non-enhanced PCM configurations.

Fig. 7. Photographs progression during melting with $\alpha=0^{\circ}$ (left), $\alpha=0^{\circ}$ (left-middle), $\alpha=0^{\circ}$ (rightmiddle), $\alpha=90^{\circ}$ (right) and $|\Delta T|=17^{\circ} \mathrm{C}$ for the HP-PCM configuration at (a) $t=30 \mathrm{~min}$ (b) $t=60 \mathrm{~min}$ and (c) $t=90 \mathrm{~min}$.

Fig. 8. Liquid fraction histories for the HP-PCM cases with $|\Delta T|=17^{\circ} \mathrm{C}$ using a copper disc (open symbols) and an acrylic disc (filled symbols) during (a) solidification and (b) melting.

Fig. 9. Effect of orientation and $|\Delta T|$ on the liquid fraction histories during solidification for the (a) HPFoil-PCM, (b) HP-Foam-PCM, (c) HP-PCM, (d) Rod-PCM, (e) Foam-PCM and (f) non-enhanced PCM configurations.

Fig. 10. Effect of orientation and $|\Delta T|$ on the liquid fraction histories during melting for the (a) HP-FoilPCM, (b) HP-Foam-PCM, (c) HP-PCM, (d) Rod-PCM, (e) Foam-PCM and (f) non-enhanced PCM configurations.

Fig. 11. Liquid fraction histories for each configuration with $|\Delta T|=17^{\circ} \mathrm{C}$ (a) solidification, $\alpha=0^{\circ}$, (b) melting, $\alpha=0^{\circ}$, (c) solidification, $\alpha=90^{\circ}$ and (d) melting, $\alpha=90^{\circ}$. 
Fig. 12. Time ratio and effectiveness for each configuration at $95 \%$ complete phase change with respect to the non-enhanced PCM case with $|\Delta T|=17^{\circ} \mathrm{C}$ (a) solidification, $\alpha=0^{\circ}$, (b) melting, $\alpha=0^{\circ}$, (c) solidification, $\alpha=90^{\circ}$ and (d) melting, $\alpha=90^{\circ}$. 


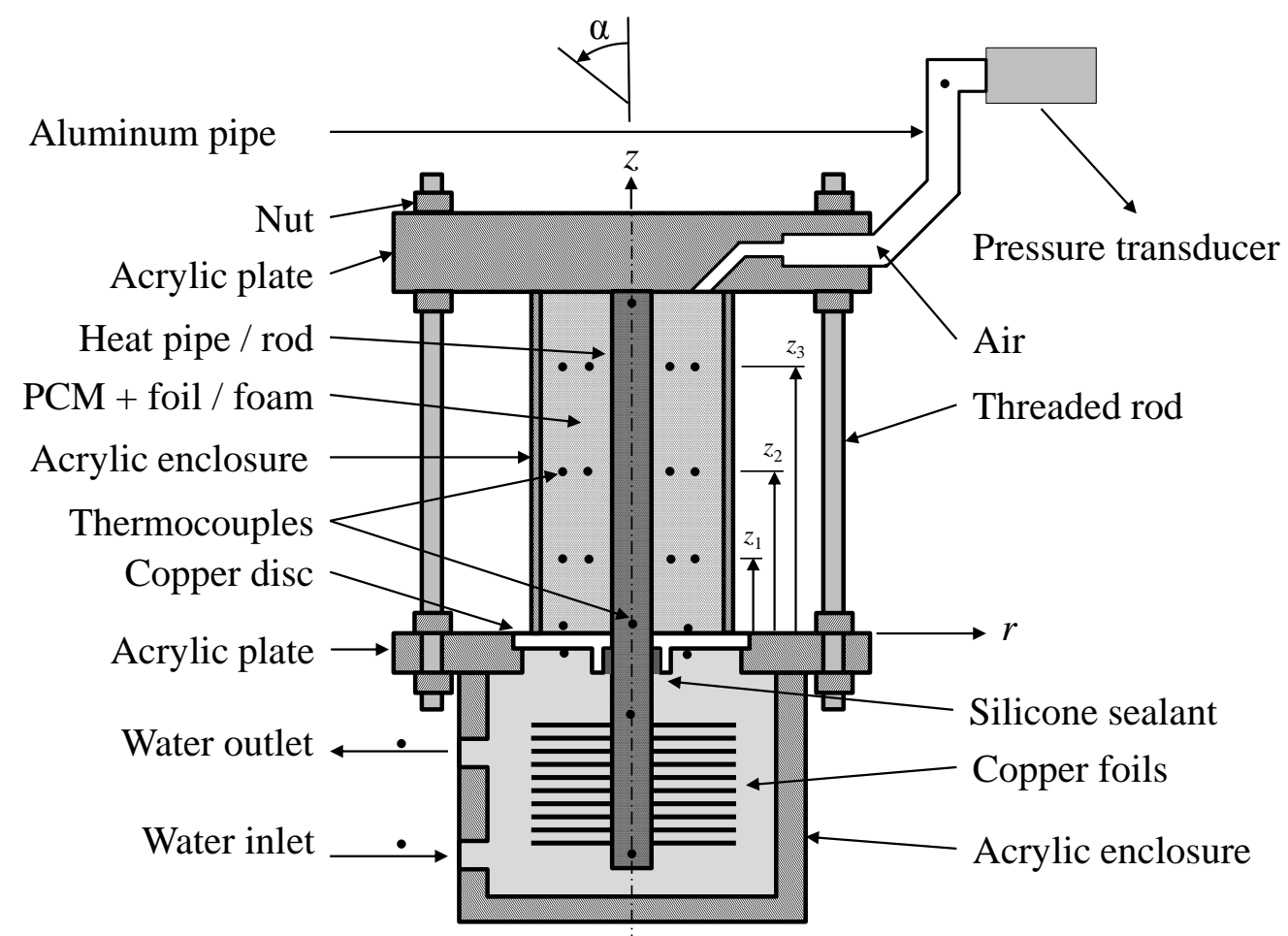

(a) central cross section parallel to the right side view (plane of symmetry)

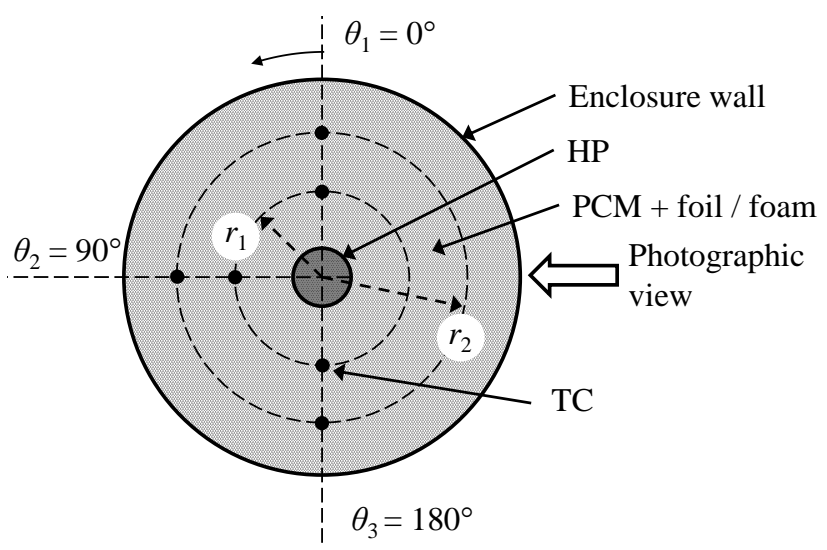

(b) top view

Fig. 1. Schematic of the experimental apparatus (a) central cross section parallel to the right side view (plane of symmetry) and (b) top view. 


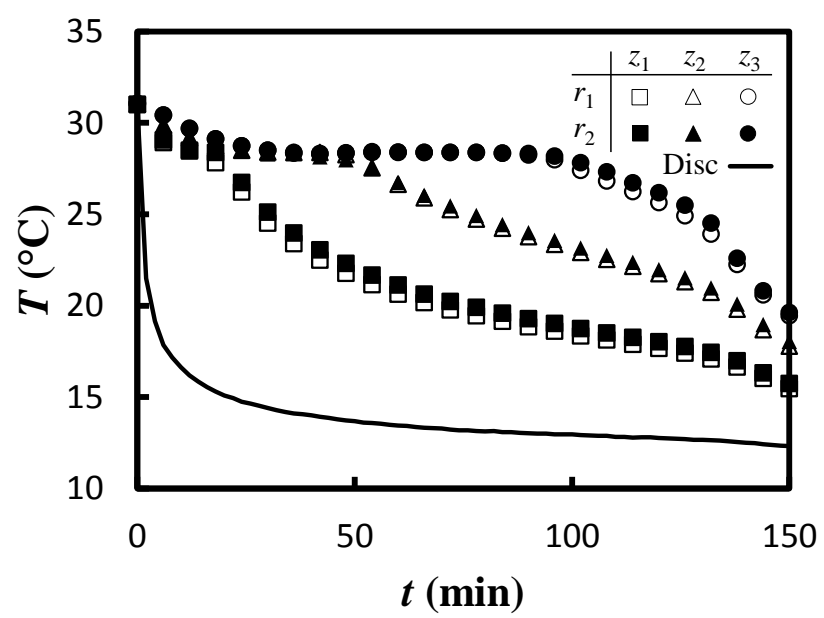

(a) Foam-PCM

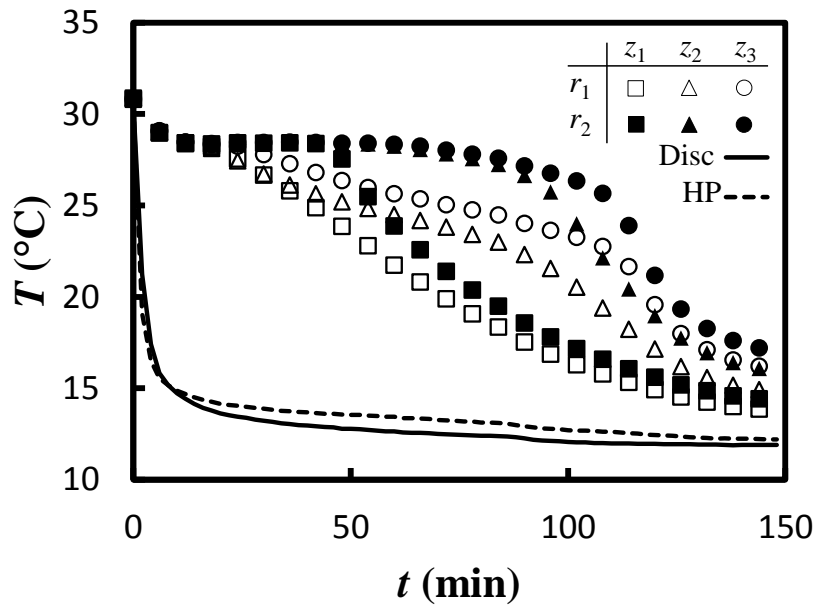

(b) HP-PCM

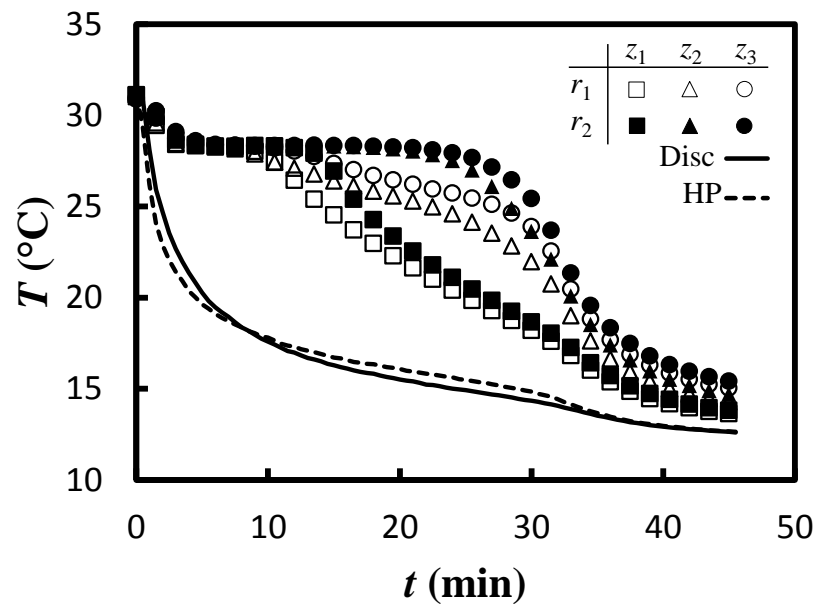

(c) HP-Foam-PCM

Fig. 2. Temperature distribution during solidification with $\alpha=0^{\circ}$ and $|\Delta T|=17^{\circ} \mathrm{C}$ for the (a) Foam-PCM,

(b) HP-PCM and (c) HP-Foam-PCM configurations. 


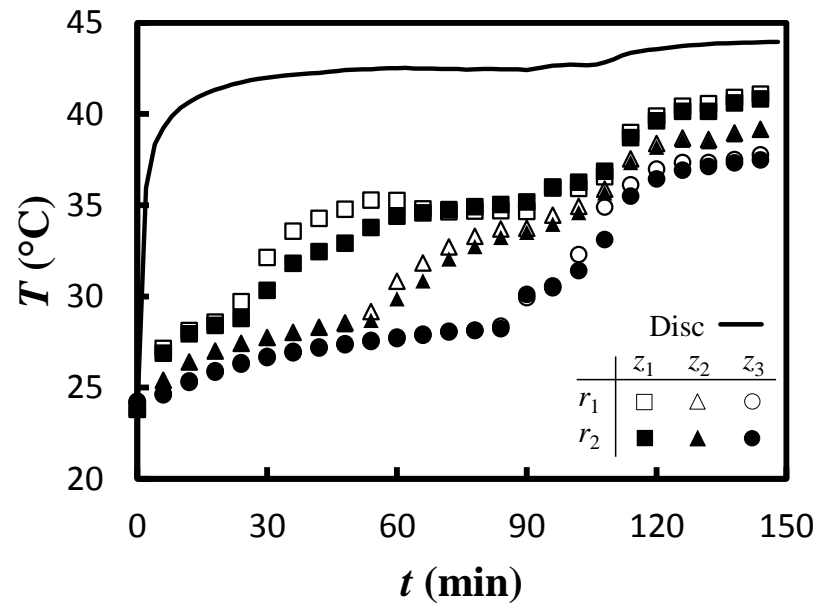

(a) Foam-PCM

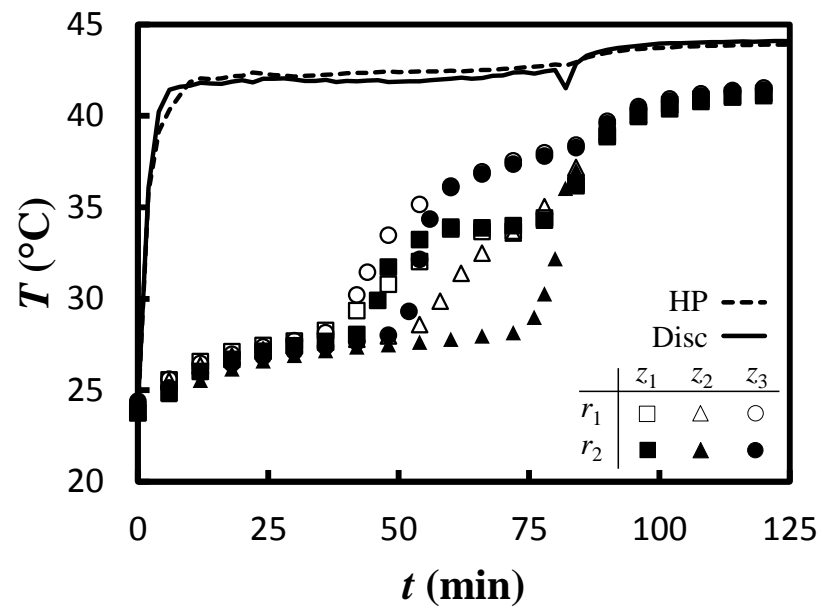

(b) HP-PCM

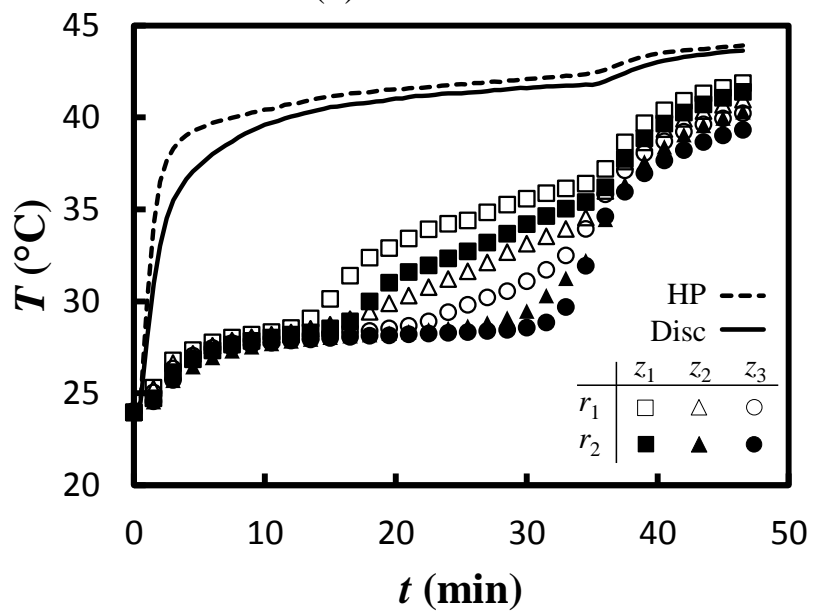

(c) HP-Foam-PCM

Fig. 3. Temperature distribution during melting with $\alpha=0^{\circ}$ and $|\Delta T|=17^{\circ} \mathrm{C}$ for the (a) Foam-PCM, (b) HP-PCM and (c) HP-Foam-PCM configurations. 

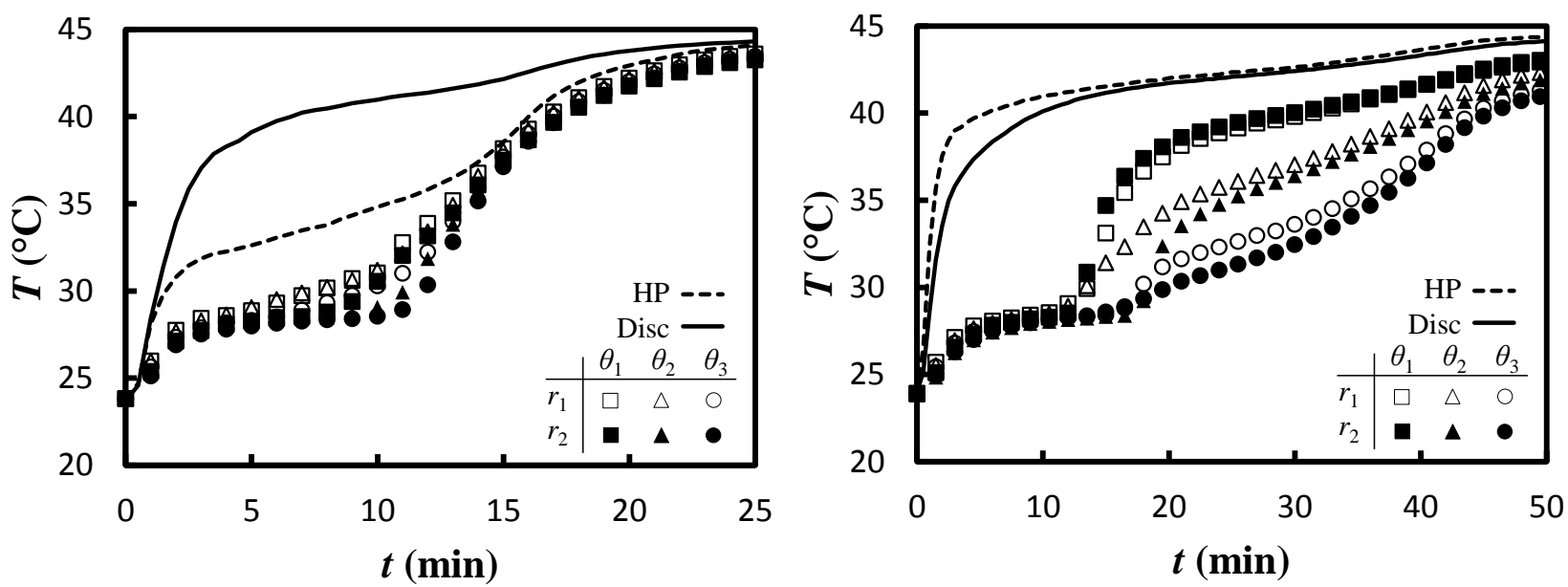

(a) $z_{1}=15 \mathrm{~mm}$
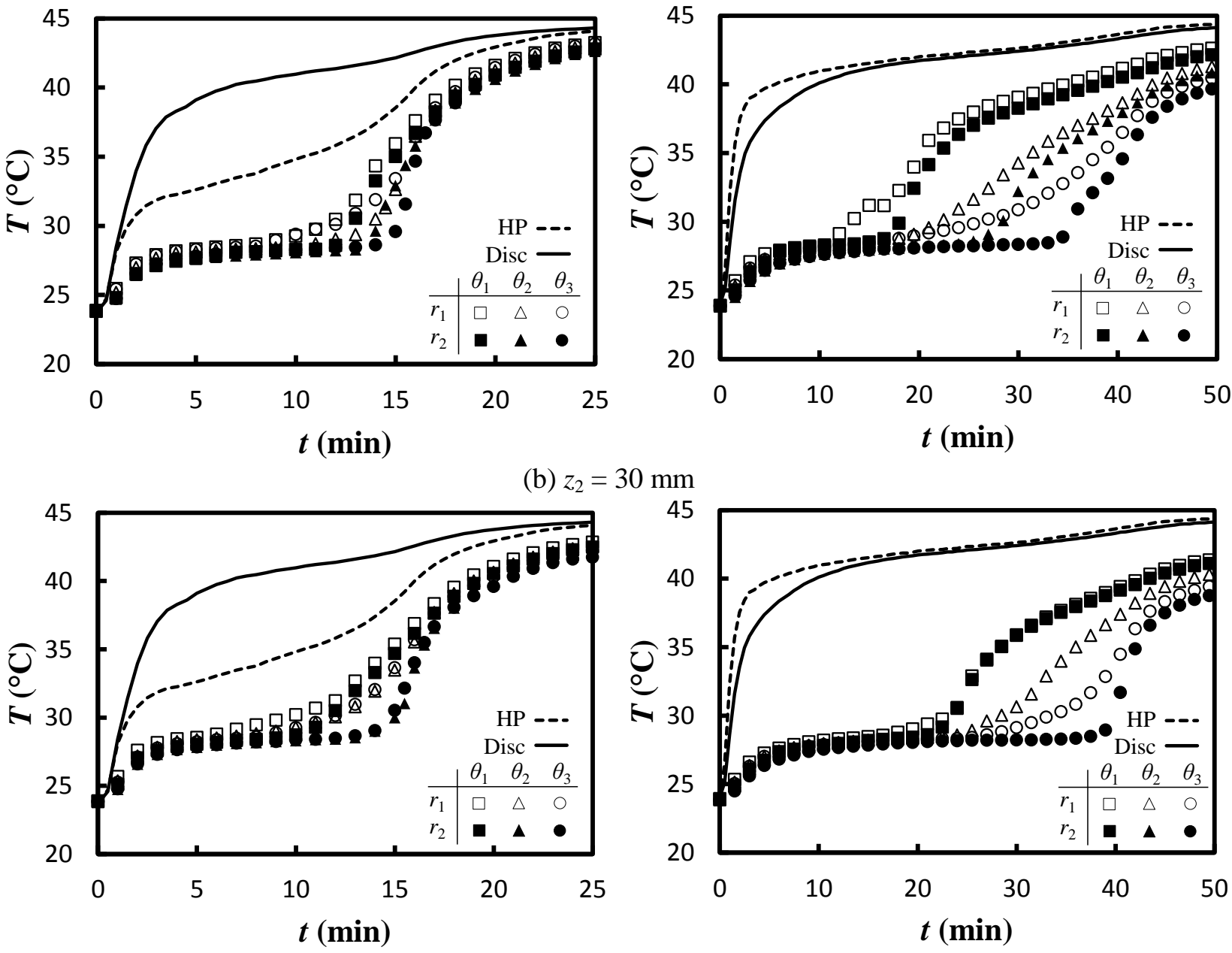

(c) $z_{3}=45 \mathrm{~mm}$

Fig. 4. Temperature distribution during melting for the HP-Foil-PCM (left) and HP-Foam-PCM (right) configurations with $|\Delta T|=17^{\circ} \mathrm{C}$ and $\alpha=90^{\circ}$ for (a) $z_{1}=15 \mathrm{~mm}$ (b) $z_{2}=30 \mathrm{~mm}$ and (c) $z_{3}=45 \mathrm{~mm}$. 


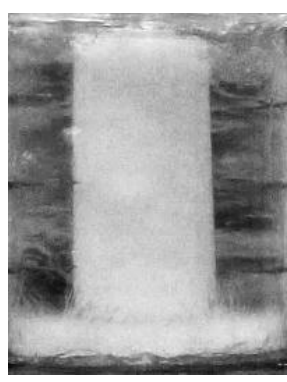

(a) HP-PCM
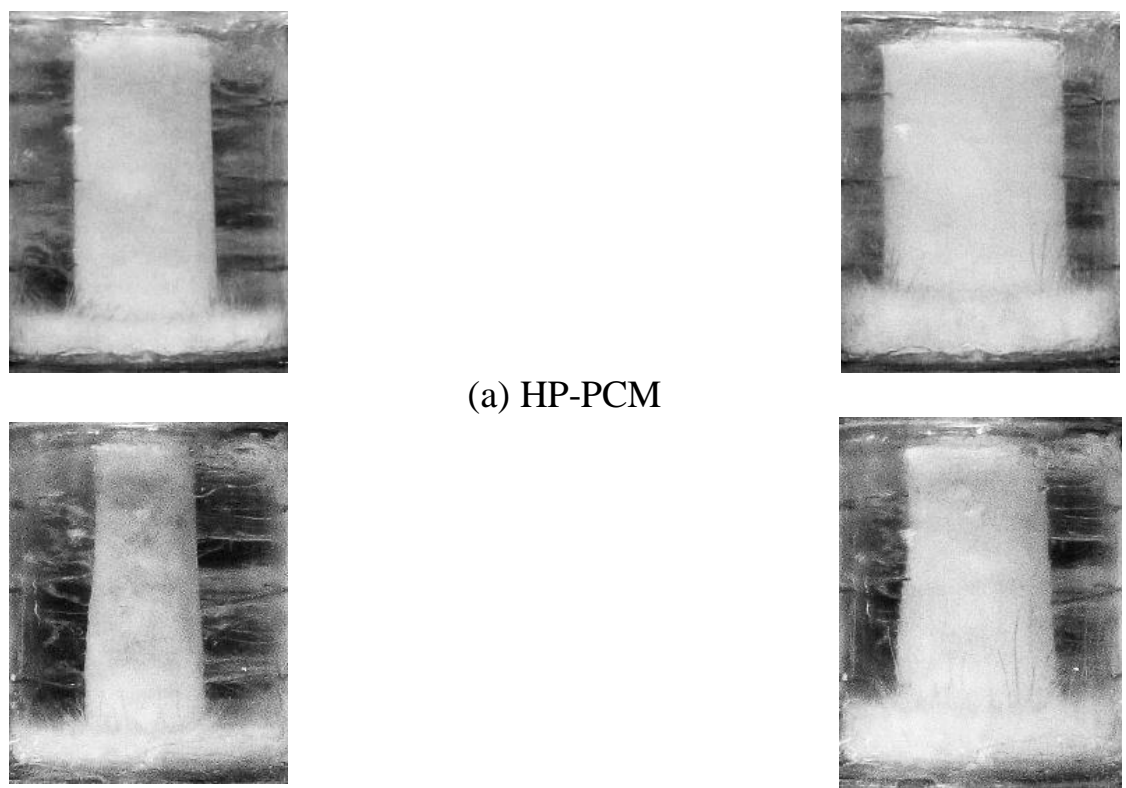

(b) Rod-PCM
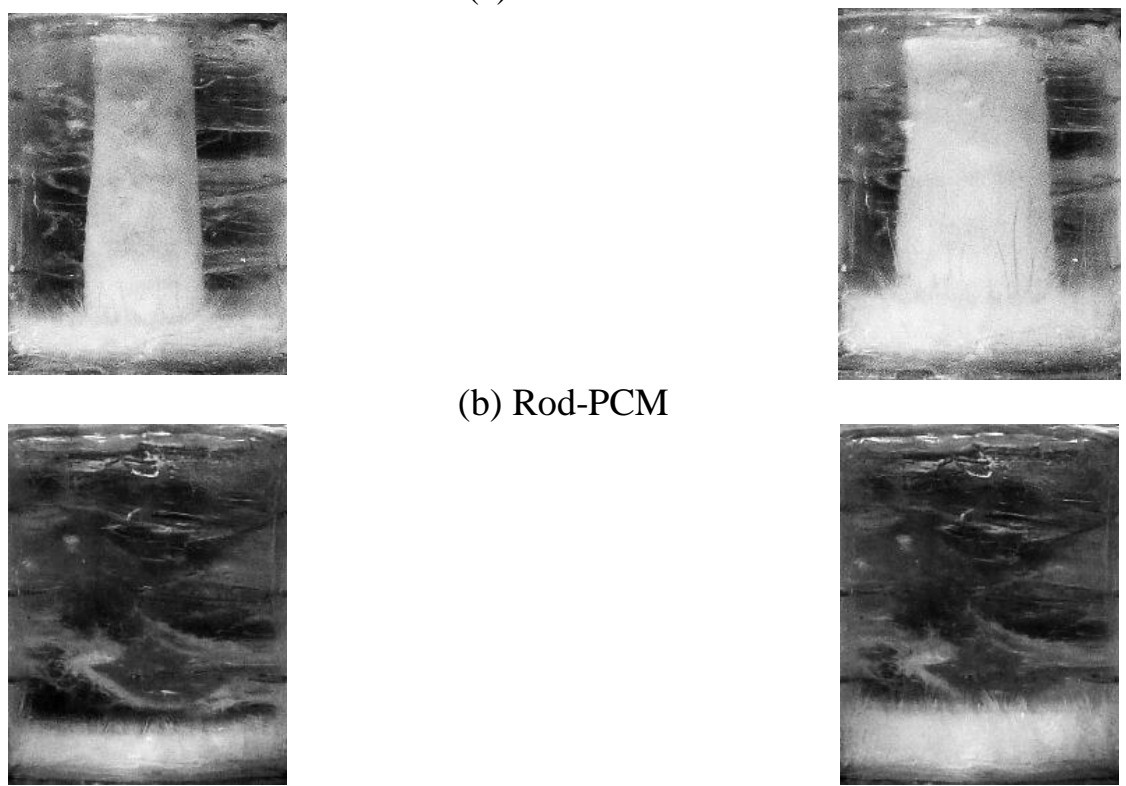

(c) non-enhanced PCM

Fig. 5. Photographs during solidification with $\alpha=0^{\circ}$ and $|\Delta T|=17^{\circ} \mathrm{C}$ for the (a) HP-PCM, (b) Rod-PCM and (c) non-enhanced PCM configurations at $t=15 \mathrm{~min}$ (left) and $t=30 \mathrm{~min}$ (right). 

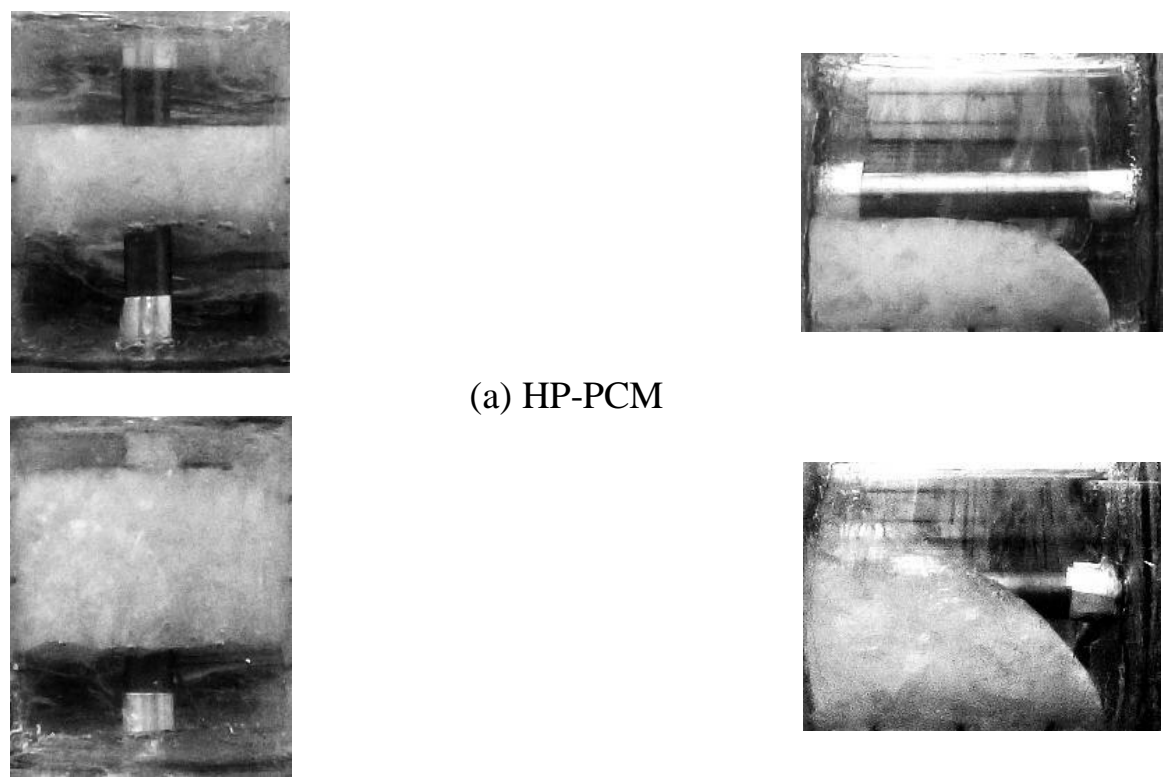

(a) HP-PCM
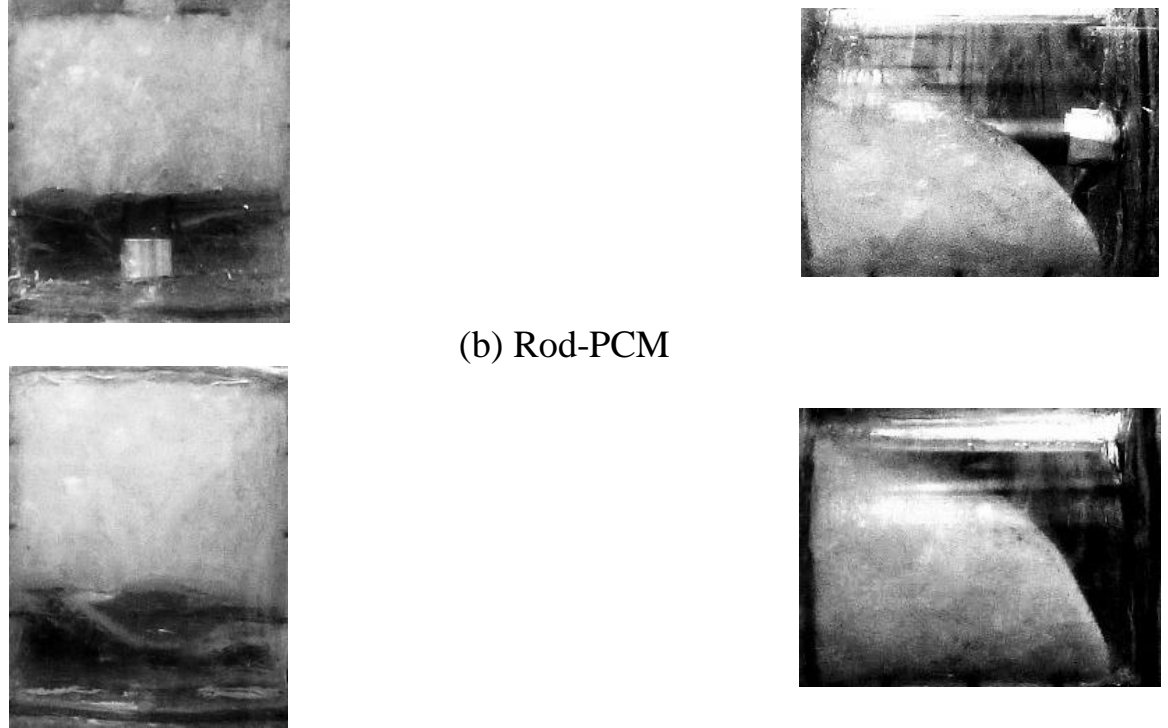

(b) Rod-PCM

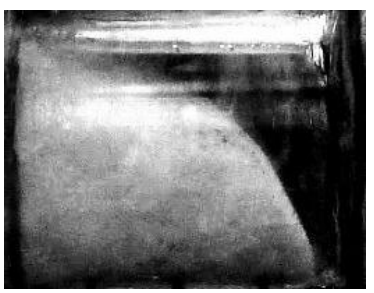

(c) non-enhanced PCM

Fig. 6. Photographs during melting at $t=60$ min with $\alpha=0^{\circ}$ (left), $\alpha=90^{\circ}$ (right) and $|\Delta T|=17^{\circ} \mathrm{C}$ for the (a) HP-PCM, (b) Rod-PCM and (c) non-enhanced PCM configurations. 


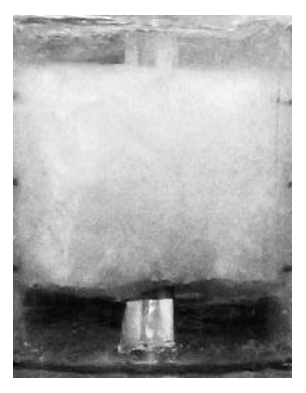

$\alpha=0^{\circ}$

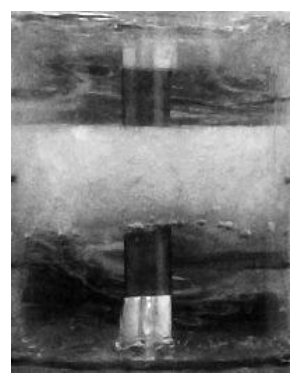

$\alpha=0^{\circ}$

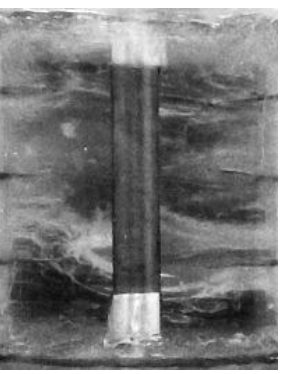

$$
\alpha=0^{\circ}
$$

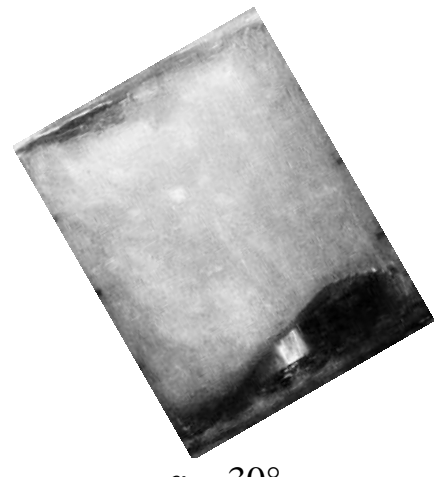

$\alpha=30^{\circ}$

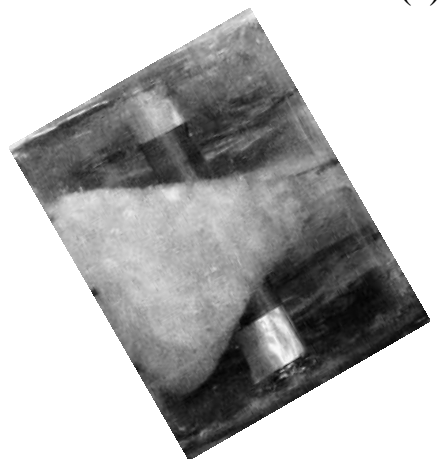

$\alpha=30^{\circ}$

(b) $t=60 \mathrm{~min}$

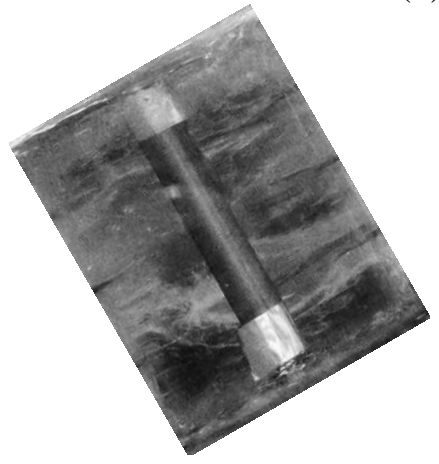

$\alpha=30^{\circ}$
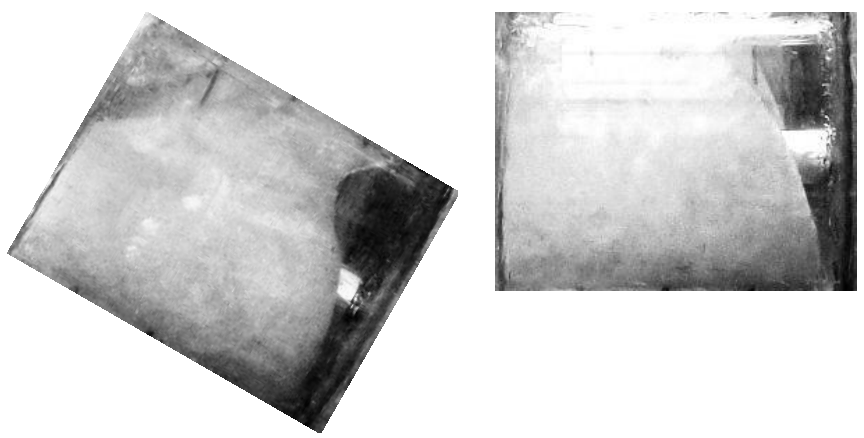

$$
\alpha=60^{\circ}
$$

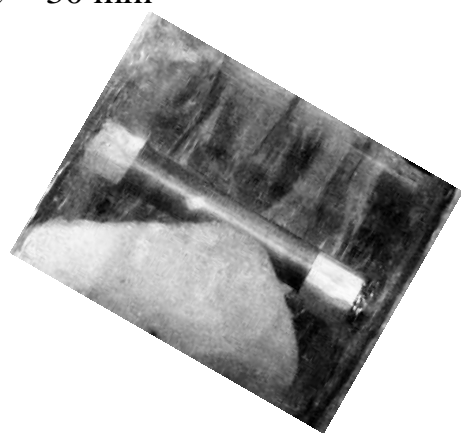

$$
\alpha=60^{\circ}
$$

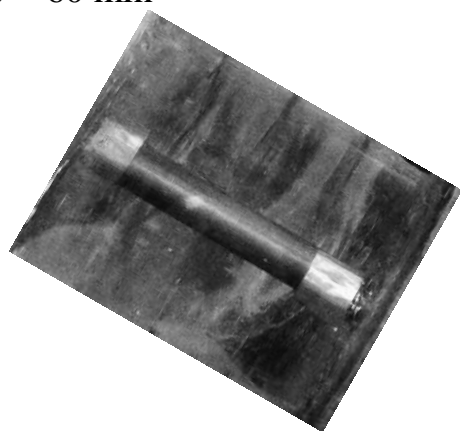

(c) $t=90 \mathrm{~min}$

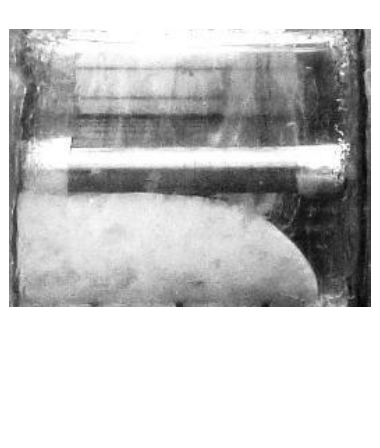

$\alpha=90^{\circ}$

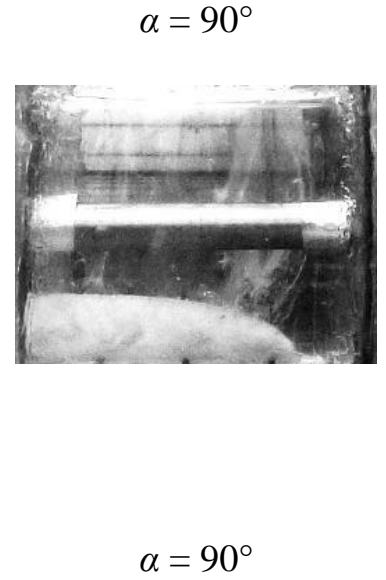

$\alpha=90^{\circ}$

Fig. 7. Photographs progression during melting with $\alpha=0^{\circ}$ (left), $\alpha=0^{\circ}$ (left-middle), $\alpha=0^{\circ}$ (rightmiddle), $\alpha=90^{\circ}$ (right) and $|\Delta T|=17^{\circ} \mathrm{C}$ for the HP-PCM configuration at (a) $t=30 \mathrm{~min}$ (b) $t=60 \mathrm{~min}$ and (c) $t=90 \mathrm{~min}$. 


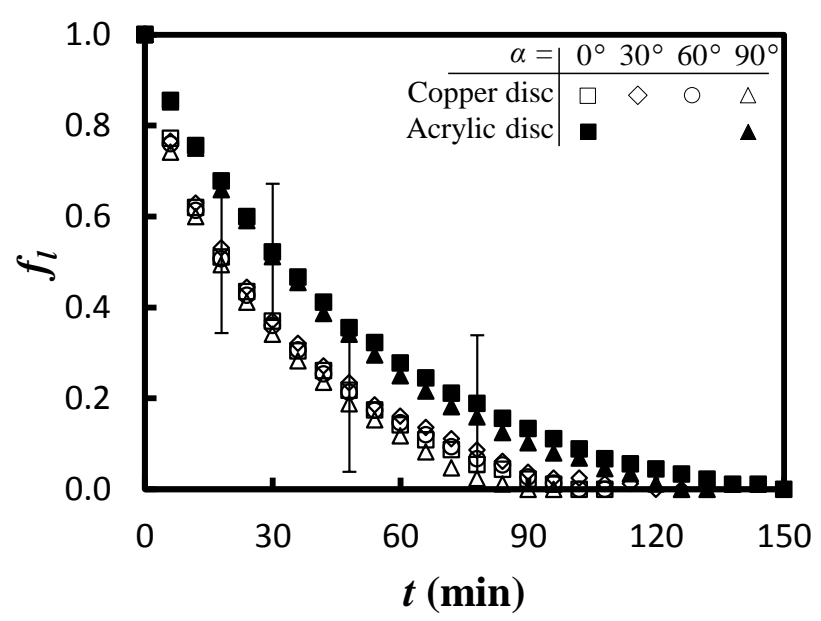

(a) solidification

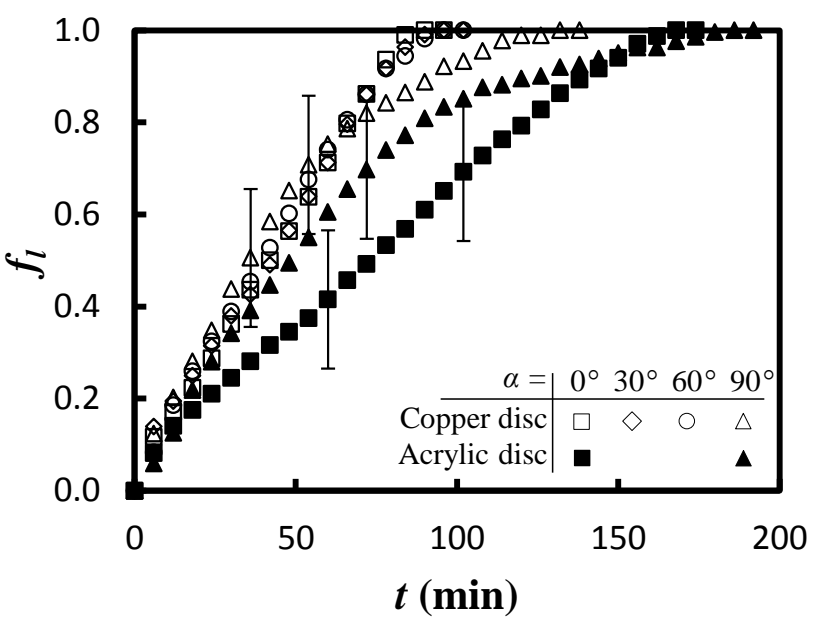

(b) melting

Fig. 8. Liquid fraction histories for the HP-PCM cases with $|\Delta T|=17^{\circ} \mathrm{C}$ using a copper disc (open symbols) and an acrylic disc (filled symbols) during (a) solidification and (b) melting. 

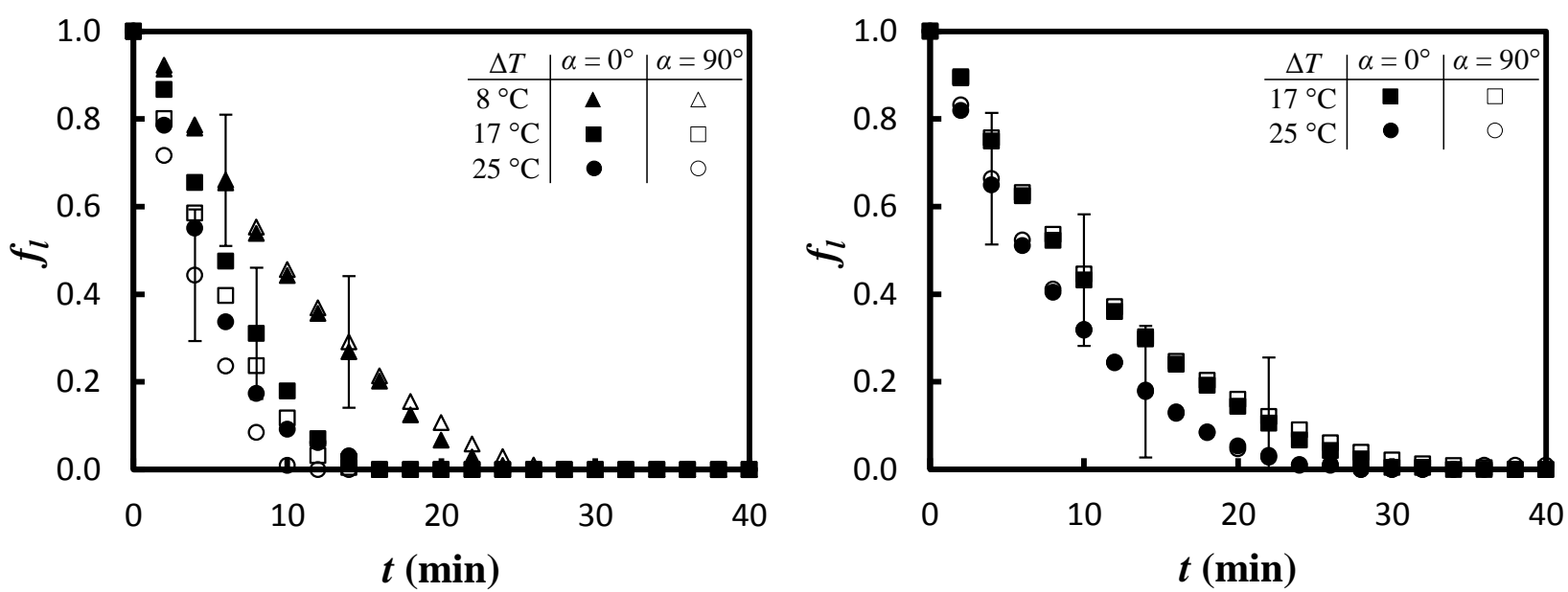

(a) HP-Foil-PCM

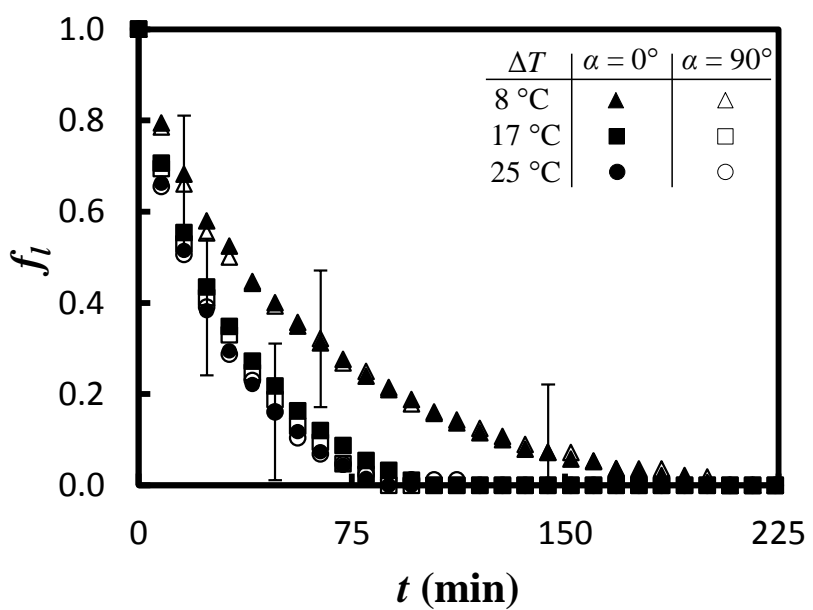

(b) HP-Foam-PCM

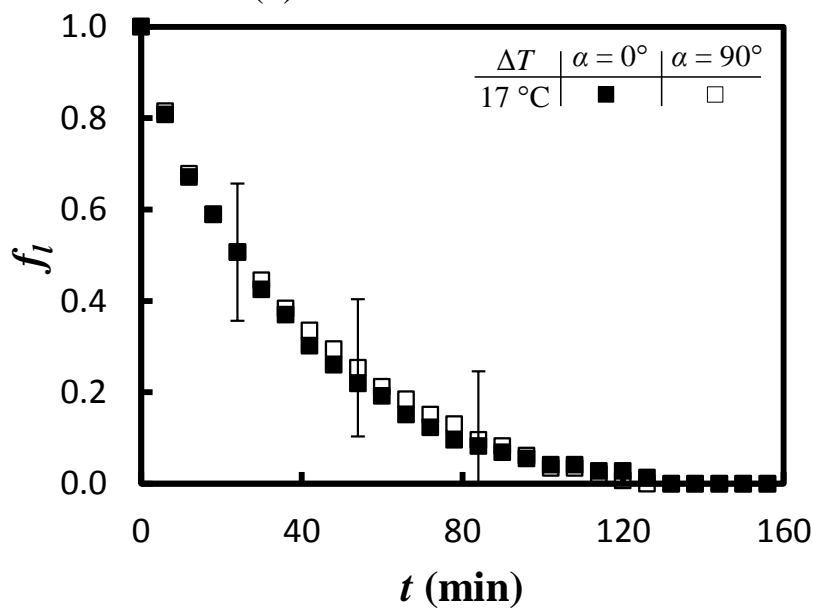

(c) HP-PCM

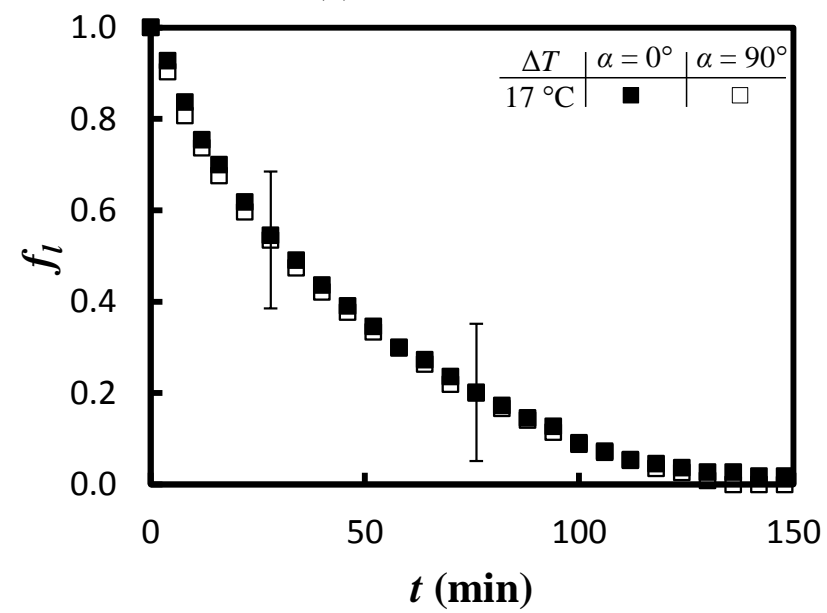

(e) Foam-PCM

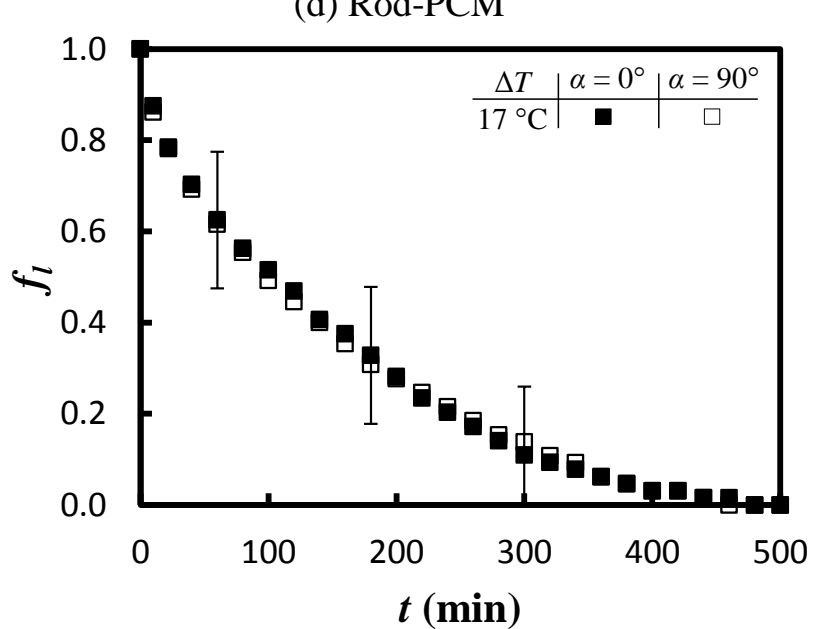

(f) non-enhanced PCM

Fig. 9. Effect of orientation and $|\Delta T|$ on the liquid fraction histories during solidification for the (a) HP-

Foil-PCM, (b) HP-Foam-PCM, (c) HP-PCM, (d) Rod-PCM, (e) Foam-PCM and (f) non-enhanced PCM configurations. 


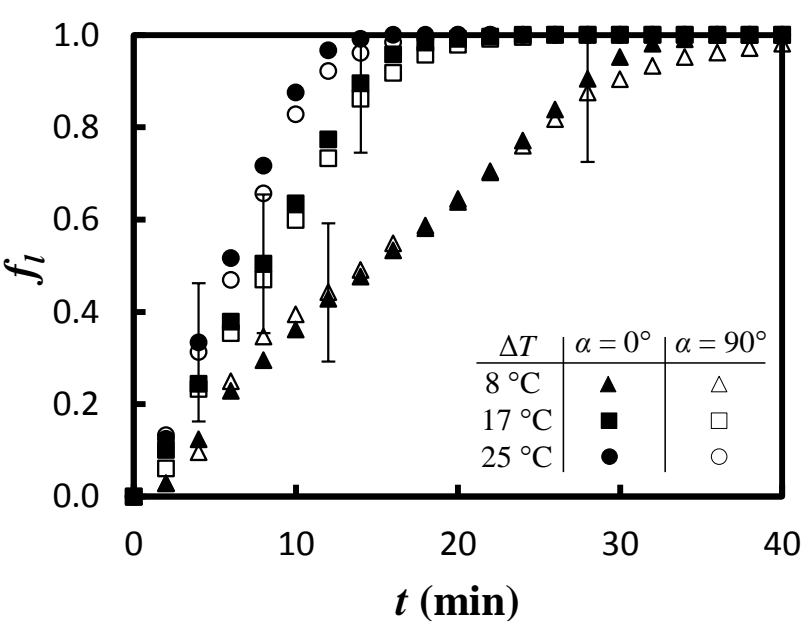

(a) HP-Foil-PCM

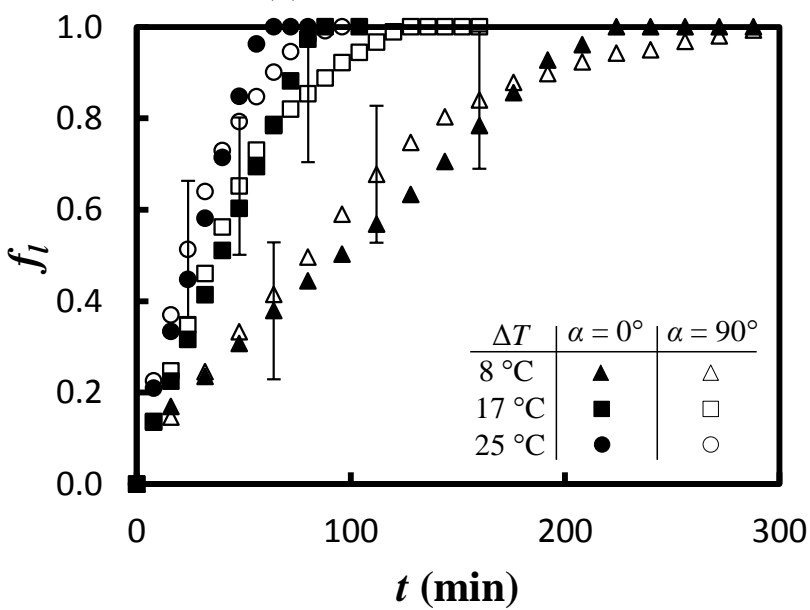

(c) HP-PCM

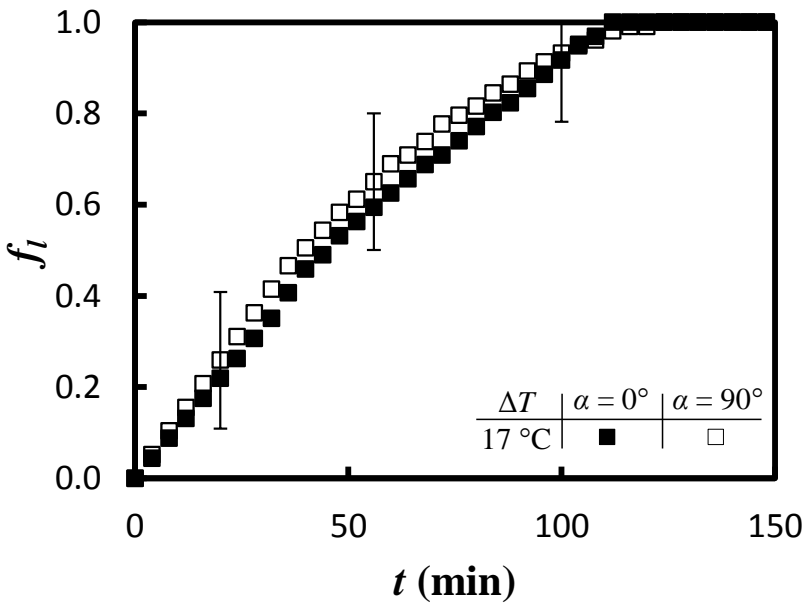

(e) Foam-PCM

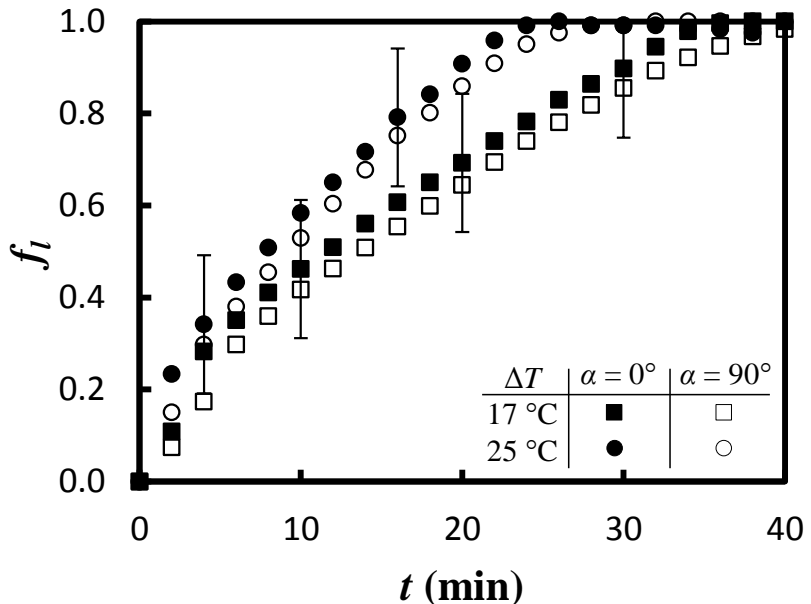

(b) HP-Foam-PCM

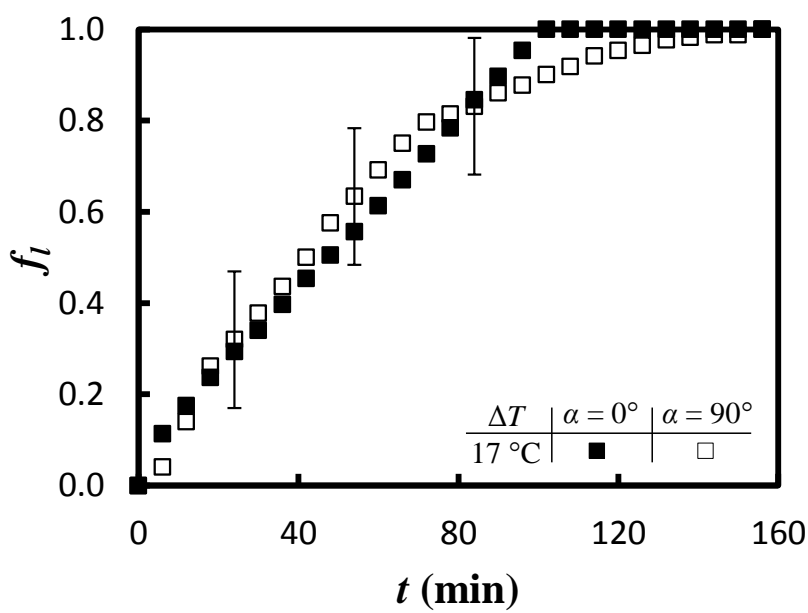

(d) Rod-PCM

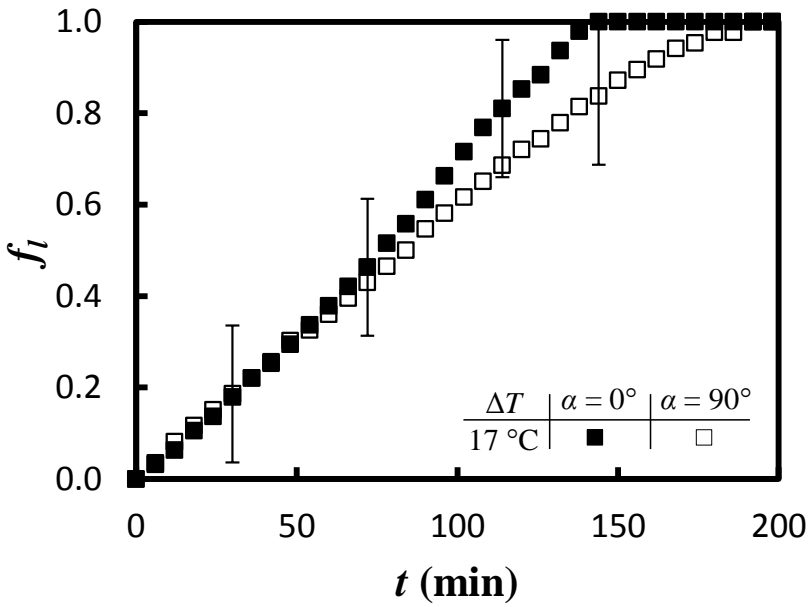

(f) non-enhanced PCM

Fig. 10. Effect of orientation and $|\Delta T|$ on the liquid fraction histories during melting for the (a) HP-FoilPCM, (b) HP-Foam-PCM, (c) HP-PCM, (d) Rod-PCM, (e) Foam-PCM and (f) non-enhanced PCM configurations. 

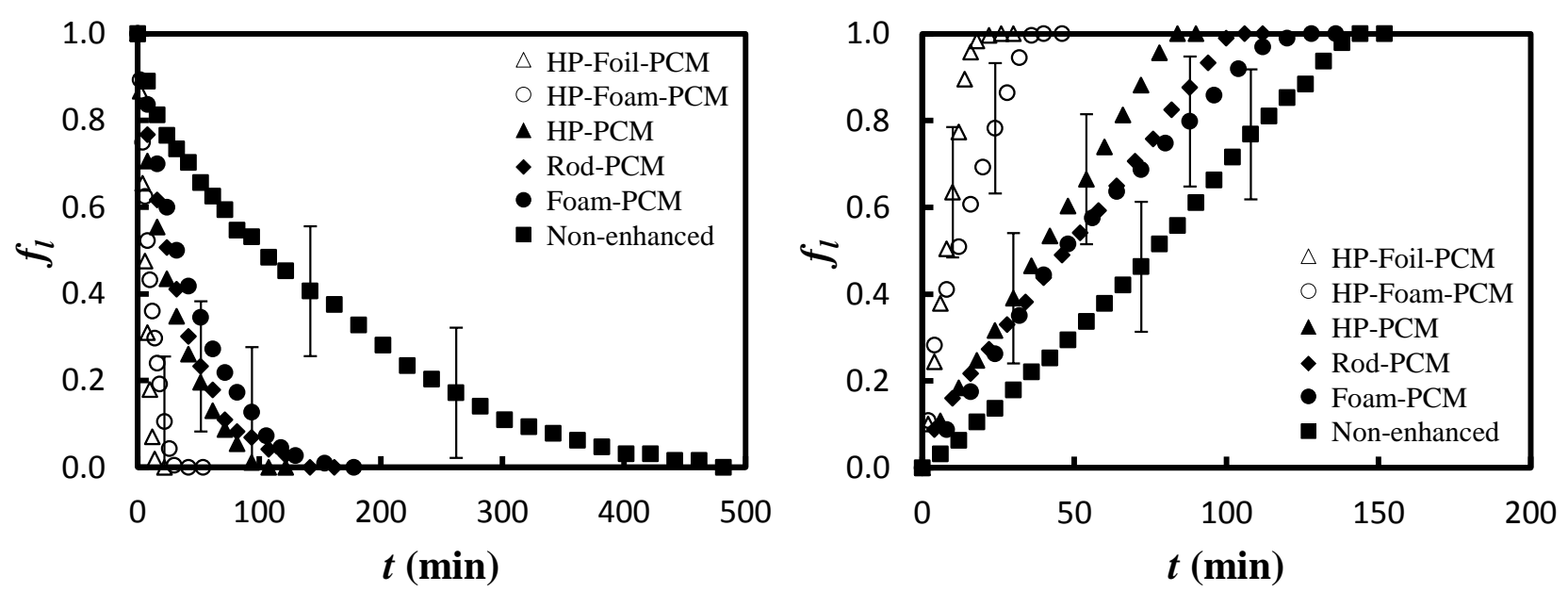

(a) solidification, $\alpha=0^{\circ}$

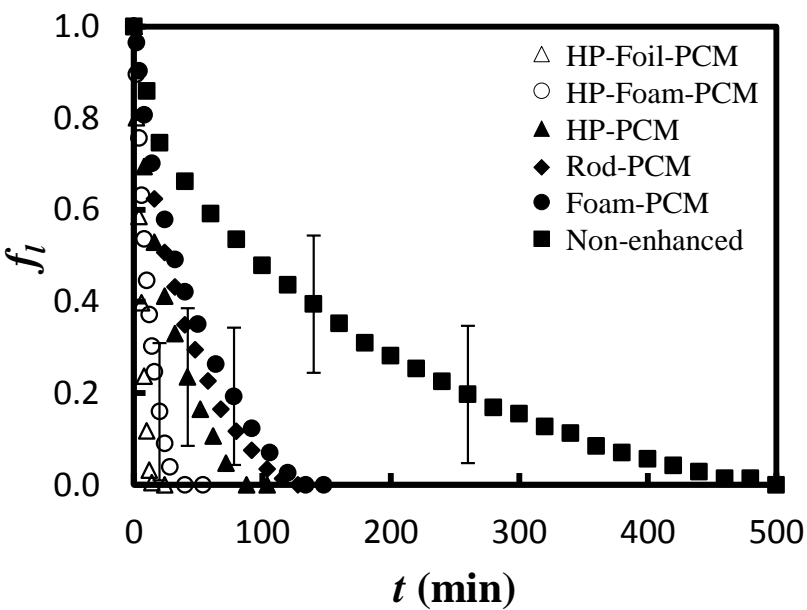

(c) solidification, $\alpha=90^{\circ}$

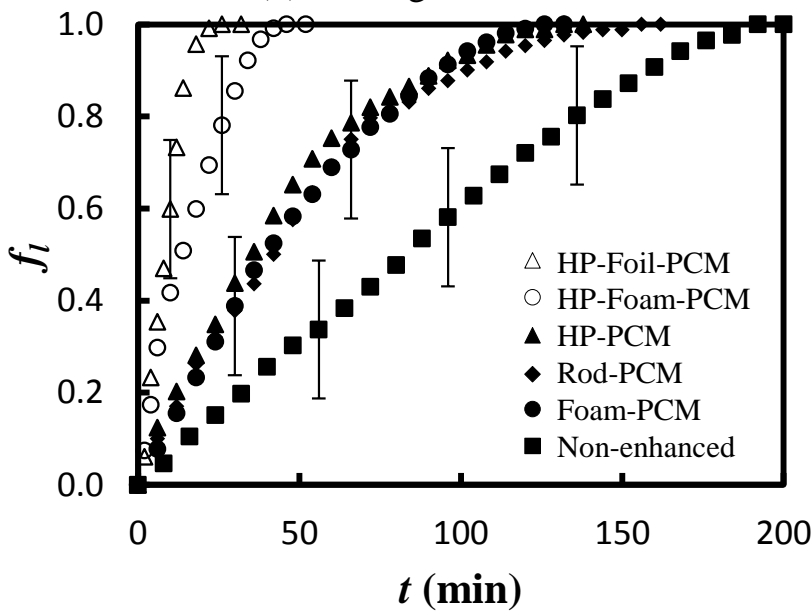

(d) melting, $\alpha=90^{\circ}$

Fig. 11. Liquid fraction histories for each configuration with $|\Delta T|=17^{\circ} \mathrm{C}$ (a) solidification, $\alpha=0^{\circ}$, (b) melting, $\alpha=0^{\circ}$, (c) solidification, $\alpha=90^{\circ}$ and (d) melting, $\alpha=90^{\circ}$. 


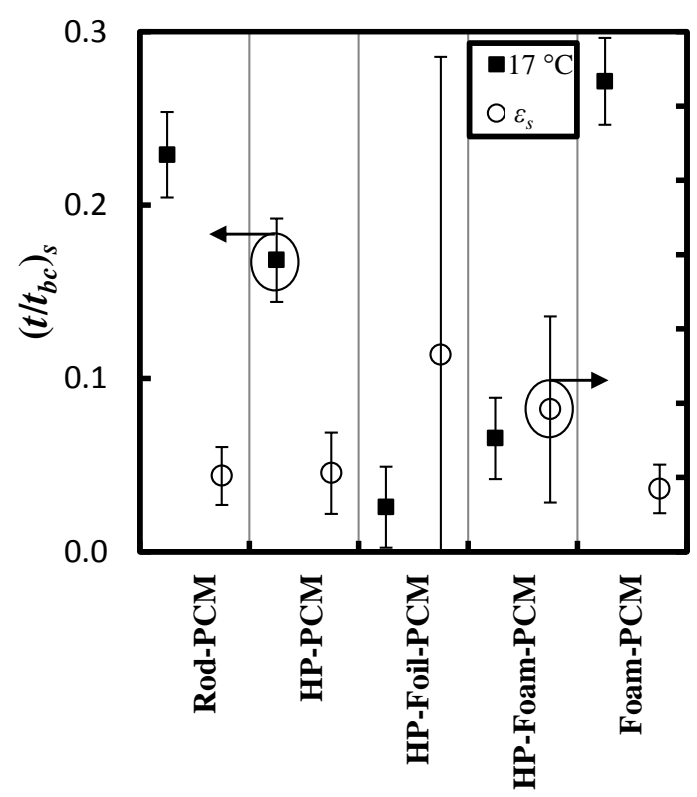

(a) solidification, $\alpha=0^{\circ}$

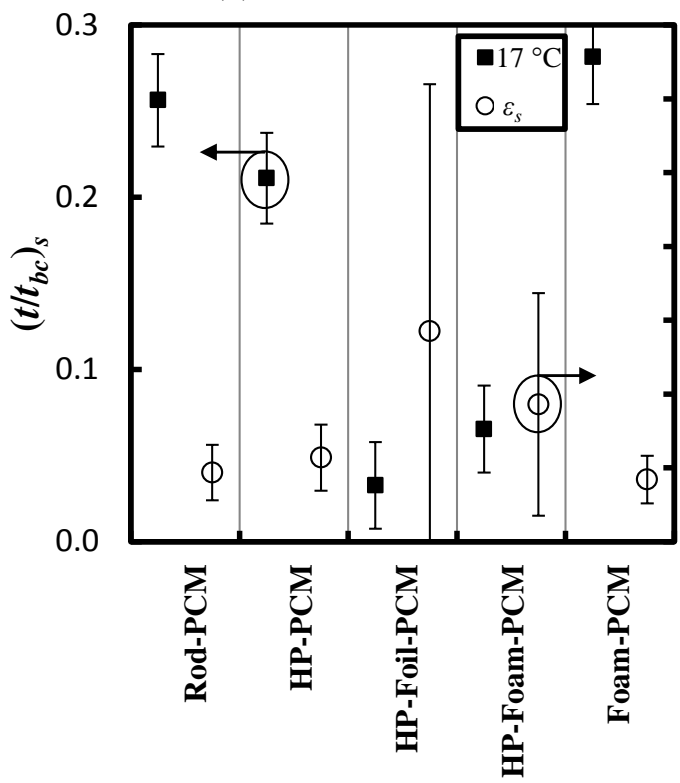

(c) solidification, $\alpha=90^{\circ}$

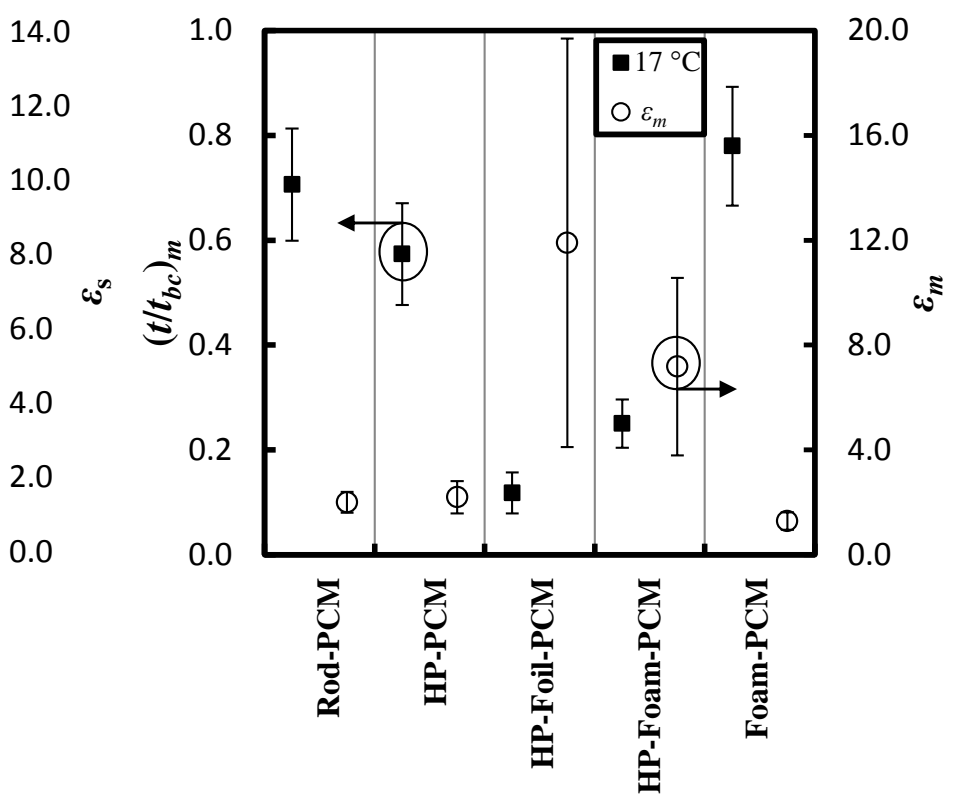

(b) melting, $\alpha=0^{\circ}$

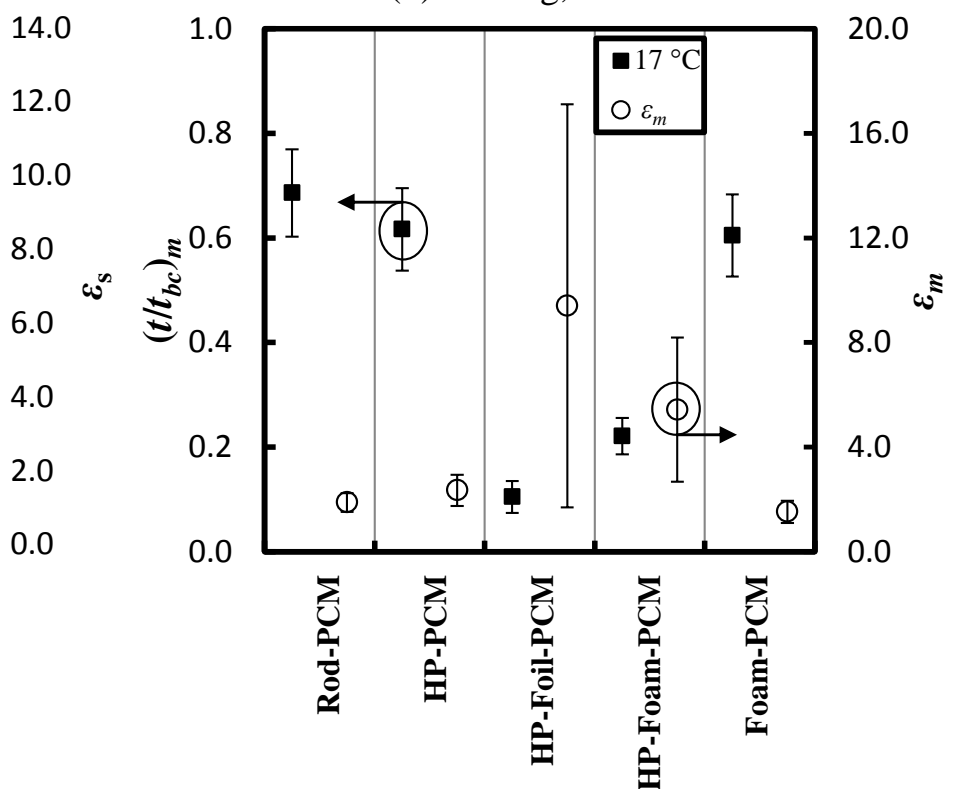

(d) melting, $\alpha=90^{\circ}$

Fig. 12. Time ratio and effectiveness for each configuration at $95 \%$ complete phase change with respect

to the non-enhanced PCM case with $|\Delta T|=17^{\circ} \mathrm{C}$ (a) solidification, $\alpha=0^{\circ}$, (b) melting, $\alpha=0^{\circ}$, (c) solidification, $\alpha=90^{\circ}$ and (d) melting, $\alpha=90^{\circ}$. 